\title{
Cognitive dysfunction in major depression: From assessment to novel therapies
}

DOI:

10.1016/j.pharmthera.2019.05.013

\section{Document Version}

Accepted author manuscript

Link to publication record in Manchester Research Explorer

\section{Citation for published version (APA):}

Atique-ur-rehman, H., \& Neill, J. C. (2019). Cognitive dysfunction in major depression: From assessment to novel therapies. Pharmacology \& therapeutics. https://doi.org/10.1016/j.pharmthera.2019.05.013

\section{Published in:}

Pharmacology \& therapeutics

\section{Citing this paper}

Please note that where the full-text provided on Manchester Research Explorer is the Author Accepted Manuscript or Proof version this may differ from the final Published version. If citing, it is advised that you check and use the publisher's definitive version.

\section{General rights}

Copyright and moral rights for the publications made accessible in the Research Explorer are retained by the authors and/or other copyright owners and it is a condition of accessing publications that users recognise and abide by the legal requirements associated with these rights.

\section{Takedown policy}

If you believe that this document breaches copyright please refer to the University of Manchester's Takedown Procedures [http://man.ac.uk/04Y6Bo] or contact uml.scholarlycommunications@manchester.ac.uk providing relevant details, so we can investigate your claim.

\section{OPEN ACCESS}




\section{Accepted Manuscript}

Cognitive dysfunction in major depression: From assessment to novel therapies

Hafsa Atique-Ur-Rehman, Joanna C. Neill

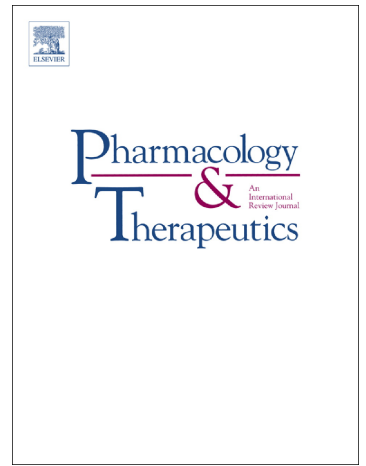

PII: S0163-7258(19)30096-8

DOI: https://doi.org/10.1016/j.pharmthera.2019.05.013

Reference: JPT 7373

To appear in:

Pharmacology and Therapeutics

Please cite this article as: H. Atique-Ur-Rehman and J.C. Neill, Cognitive dysfunction in major depression: From assessment to novel therapies, Pharmacology and Therapeutics, https://doi.org/10.1016/j.pharmthera.2019.05.013

This is a PDF file of an unedited manuscript that has been accepted for publication. As a service to our customers we are providing this early version of the manuscript. The manuscript will undergo copyediting, typesetting, and review of the resulting proof before it is published in its final form. Please note that during the production process errors may be discovered which could affect the content, and all legal disclaimers that apply to the journal pertain. 


\section{Cognitive Dysfunction in Major Depression: From Assessment to Novel Therapies}

Hafsa Atique-Ur-Rehman ${ }^{\mathrm{a}}$ and Joanna C. Neill, ${ }^{\mathrm{b}, *}$ joanna.neill@manchester.ac.uk

aPre-Registration Pharmacist, Inpatient Pharmacy, Manchester University NHS Foundation Trust, Oxford Road, Manchester, M13 9WL

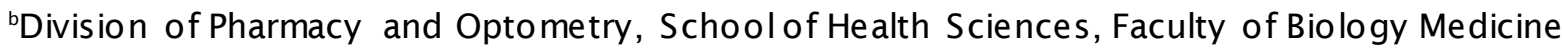
and Health, University of Manchester, Manchester, M13 9PT, Website: b-neuro.com

Corresponding author.

\section{Abst ract}

Major depressive disorder (MDD) is a disabling disease associated with profound functional impairment. Cognitive deficits, increasingly recognized as a core feature of MDD, reduce educational, occupational and social outcomes, and impair quality of life and functionality. Unlike cognitive impairments associated with schizophrenia (CIAS), cognitive impairments in depression have been under diagnosed and are poorly understood. Consensus has yet to be reached regarding the nature of these deficits, their appropriate assessment and treatment options. It is unclear whether existing treatments have an impact on cognitive deficits. Here, we conduct a thorough and extensive review of recent published work on this unmet clinical need (2014-2018). We evaluate the validity of available assessment tools, and examine the evidence for efficacy of current and novel pharmacological therapies. From our analysis, we have established that cognitive deficits are indeed widespread in MDD patients. The THINC-it tool, a recently validated and sensitive cognitive assessment instrument, shows promise for earlier detection of Cognitive Impairment Associated with MDD and could be easily applied in clinical practice. Several potential novel therapies are emerging. Methodological inconsistencies and small underpowered studies, however, have led to conflicting results and inconclusive evidence. Our recommendations include: development of a standardized neurocognitive test battery for MDD, improving clinical trial design, investigating sex differences, and patient stratification. These changes should support the development of improved therapeutic strategies for cognitive dysfunction in MDD patients, as well as facilitate their use in clinical practice.

\section{Keywords}


Cognition, major depressive disorder, cognitive deficits, neuroinflammation,

pharmacotherapy, patient stratification, THINC-it,

\section{List of Abbreviations}

ACC Anterior cingulate cortex

BDI Beck Depression Inventory

BD Bipolar depression

CRP C-reactive protein

CANTAB Cambridge Neuropsychological Test Automated Battery

CR Cognitive remediation

CPFQ

Cognitive and Physical Functioning Questionnaire

COX-2

Cyclooxygenase-2

DMN

Default mode network

DSST

Digit Symbol Substitution Test

DA

Dopamine

DLPFC

Dorsolateral prefrontal cortex

DMPFC

Dorsomedial prefrontal cortex

ECT

EPO

Electroconvulsive therapy

FED

Erythropoietin

fMRI

HDRS

IL-1 $\beta$

IL-6

LLD

LF

First-episode depression

Functional MRI

Hamilton Depression Rating Scale

Interleukin 1 beta

Interleukin 6

Late-life depression

Life functioning

LDX

MRI

Lisdexamfetamine

MDD

Magnetic resonance imaging

MDE

MATRICS

Major depressive disorder

MADRS

Major depressive episode

NA

PDQ-5

PFC

RCT

rMDD

RBANS

RAVLT

SAMe

SSRI

Measurement and Treatment Research to Improve Cognition in Schizophrenia Montgomery-Åsberg Depression Rating Scale

Norepinephrine

Perceived Deficits Questionnaire for Depression-5-item

Pre-frontal cortex

Randomised-controlled trial

Remitted major depressive disorder

Repeatable Battery for the Assessment of Neuropsychological Status

Rey Auditory Verbal Learning Test

S-adenosylmethionine

SNRI

Selective serotonin reuptake inhibitors

TMT

Serotonin-norepinephrine reuptake inhibitors

TRD

Trail Making Test

Treatment-resistant depression

TCA

Tricyclic antidepressant

TNF- $\alpha$

Tumour necrosis factor alpha

UD

Unipolar depression 


\section{Introduction}

Major depressive disorder (MDD) is a highly prevalent and disabling disease. In the United States, 1 in 5 adults experience a major depressive episode (MDE) within the ir lifetime (Mattingly et al., 2016). Associated with 23-fold increases in social disability and 5 -fold increases in disability-related absenteeism, MDD may cause psychosocial impairments equal to, or greater than, chronic illnesses such as diabetes and osteoarthritis (Papakostas et al., 2004). Additionally, depressed patients consistently experience poorer social functioning and higher levels of domestic stress, financial strain, and workplace limitations (Clark et al., 2016).

Cognitive deficits are a core feature of depression. Within the Diagnostic and Statistical Manual of Mental Disorders' (DSM-V) definition of MDD, these relate to "diminished ability to think or concentrate, or indecisiveness" (Regier et al., 2013). Cognitive impairment relates to deficits in attention, executive functioning, working memory, processing speed, learning, episodic memory, and/or visuospatial memory domains. Potentially contributing to anhedonia and psychomotor retardation, cognitive function can be made worse by sleep disruption and fatigue. Conversely, impairment in information processing may be masked by these same symptoms, compounding existing difficulties in recognition and treatment. In a 3-year intervention study, $94 \%$ of patients experienced cognitive deficits during an episode of MDD. Of these, $45 \%$ had persisting dysfunction during remission (Mattingly et al., 2016). Despite this, only $38 \%$ of psychiatrists report using cognitive instruments to screen patients; of these, only 3\% were actually deemed appropriate (Belgaied et al., 2014).

Cognitive deficits have considerable impact, and lead to profound psychosocial impairment and disability. Effects include absenteeism, poorworkplace productivity and quality of life, increased stress and social impairments, and decreased ability to perform daily functions. Cognitive batteries indicate that processing difficulties exist both during and between MDD episodes with $95 \%$ of patients struggling with global cognition. Across all mood disorders, $50-70 \%$ of remitted patients have been reported to have cognitive impairments (Seeberg et al., 2018). MDD severity has been significantly associated with reduced cognitive performance, particularly in episodic memory, executive function and processing speed 
(Mattingly et al., 2016). Despite this, incomplete treatment and recognition correlate with higher relapse rates and poorer functional outcomes.

Our systematic review aims to conduct a landscape assessment of cognitive deficits in MDD. To do this, we aimed to establish how well cognitive dysfunction has been identified in MDD, the way it is currently measured, and what effects standard and experimental treatments have on cognitive deficits. Our ultimate goal is to provide important recommendations towards an outstanding and thus far greatly neglected need in MDD.

\section{Methods}

A systematic review was performed using PubMed and ScienceDirect databases, including specifically literature published between $2014-2018$ to identify the most recent findings in this field. In order to find all material relating to cognitive deficits, studies were identified using a broad collection of terms and then refined according to relevance. Three search groups were used, focusing on depression, cognition and treatments. Terms included: 'unipolar', 'depression', 'depressive', 'major depression', 'major depressive disorder,' AND/OR 'cognition', 'cognitive', 'neurocognition', 'neurocognitive', 'impairment', 'deficit,' AND/OR 'antidepressant', 'therapy', 'treatment', 'target' AND/OR 'CANTAB' and 'THINC'. Additional and relevant studies were also identified from the reference lists of included articles.

The studies included in the current review were all obtained as full text, peer-reviewed, written in English language, focused on MDD, and published within the last twenty years. Articles were excluded if they were duplicates, included sample sizes below 15 , existed solely as abstracts, included patients with comorbid conditions (i.e. those with bipolar, schizophrenia, schizoaffective disorder, geriatric depression, or conditions unrelated to unipolar depression), or tested interventions irrelevant to cognition. After applying these criteria, 68 articles were included in the current review (Fig. 1). We have organised our findings into three main areas: 1) measuring the prevalence and impact of cognitive deficits, 2) evaluation of the effectiveness of current antidepressant therapy on cognition, 3) evaluation of novel therapies on cognition. 


\section{Results}

\subsection{Measuring the prevalence and impact of cognitive deficits}

Given that approximately $40 \%$ of currently depressed or remitted patients report impairment in at least one domain, it follows that these deficits encompass a large part of acute disease and recovery (LeMoult $\&$ Gotlib, 2018). To understand the true impact of these, we assess their presentation in acute, remitted and first episode depression, as well as their effects on psychosocial functioning and quality of life.

\subsubsection{Cognit ive deficit s in acute and remit ted MDD}

We first aimed to establish the nature of cognitive impairments in acute and remitted MDD through analysis of the literature. A longitudinal study by Jaeger et al., 2006 examined neurocognitive deficits and disability in life functioning (LF) in MDD (Jaeger et al., 2006). Neurocognitive function was tested twice in 48 MDD patients (32 females and 16 males) hospitalised MDD patients, once at baseline in hospital, and then at 6 months, at which point depressive symptoms showed significant improvement. Despite this change, $60 \%$ of patients still scored as significantly, severely, or totally disabled at 6 months follow-up. $87.5 \%$ received pharmacological therapy at 6 months, and most individuals taking three medications at baseline later took two. Given the lack of controlled treatment regime and the 'ad libitum' prescribing, no reliable conclusion could be made regarding the direct treatment effect. A tenuous link was observed between 12 patients taking benzodiazepines and LF, where significantly poorer LF at 6 months was noted. The neurocognitive battery used tested seven cognitive domains, detailed in Table 1 , with five showing significant association with LF and psychosocial function. Executive function, attention, non-verbal, and learning domain measures were strongly associated with poor functional outcome. Non-verbal, leaning and motor function during an episode of MDD were predictive of 6-month LF. With $60 \%$ persisting as significantly or severely disabled at follow-up, this identified neurocognitive impairment as a key primary factor hindering functional recovery. Previous findings linking cognition and LF post-remission have been conflicting. A cross-sectional study by Preiss et al., 2009 examined attention, executive function and verbal memory in 97 (51 female, 46 male) unipolar depression (UD) patients during remission (Preiss et al., 2009). Significant cognitive impairments were confirmed in 
remitted patients versus controls. Although not found individually, increased depression severity correlated with poorer cognitive ability in the overall sample. All participants had a Montgomery-Åsberg Depression Rating Scale (MADRS) score below 12, indicating they were either symptom-free (0-6) or with some mild depression (7-19). Seventy-nine patients in the sample were on medication, including tricyclic antidepressants (TCAs), selective serotonin reuptake inhibitors (SSRIs), mirtazapine, or other unspecified antidepressants. Although medicated patients performed better in the Auditory Verbal Learning Test (AVLT) and Trail Making Test (TMT) Part B than non-medicated patients, the small number $(\mathrm{N}=18)$ makes conclusions less robust. This makes it difficult to discern whether cognitive impairment was a function of MDD alone or worsened by antidepressant treatment.

Cross-sectional findings by Baune et al., 2010 found the same association (Baune et al., 2010). Immediate memory and attention deficits were significant in 70 patients with previous MDD (44 female, 26 male), compared with healthy controls $(\mathrm{N}=206)$. The Mini International Neuropsychiatric Interview (MINI) assessed depression severity. Using the Repeatable Battery for the Assessment of Neuropsychological Status (RBANS), memory, delayed memory, visuospatial function, language, and attention were significantly worse in the depressed patient group. Visuospatial memory and attention were markedly worse in patients with current active depression. The lasting impact of poor cognition was apparent, highlighting that deficits may persist long after other symptom resolution and into remission. No significant sex difference was noted, although the study was somewhat under-powered for robust statistical evaluation. Mental and social capabilities were detrimentally affected by loss of attention and behavioural execution. This highlights that the relationship between MDD and cognitive deficits requires urgent attention, improved understanding, and treatment.

A systematic review by Hasselbalch et al., 2011 examined 500 remitted patients across 11 studies (Hasselbalch et al., 2011). UD patients reported impaired global cognitive function as previously shown, in addition to reduced attention, memory, and executive functioning compared with 471 healthy controls. Cognitive impairment again persisted beyond single episodes of MDD. In agreement with a lack of efficacy of antidepressant therapy noted by Priess et al., 2009, these studies also reported no significant correlations between antidepressants or cognitive test battery results. Assessment of medication on cognition, 
however, was not a primary outcome in any study. In studies by Priess et al., 2009 and WeilandFiedler et al., 2004, MADRS scores correlated with sub-syndromal depressive symptoms and poorer cognitive performance, although this finding was not replicated in other studies.

A meta-analysis by Bora et al., 2013 examined the effect of cognitive deficits on brain structure in euthymic MDD patients (Bora et al., 2013). 895 (60.7\% female) remitted patients across 27 studies were analysed. MDD patients had significantly lower global cognition scores than healthy controls. Late-onset patients presented with more severe impairments across all domains versus early-onset and control participants, particularly in processing speed, verbal memory, and executive functioning. Using voxel-based morphometry (VBM), reduced grey matter was consistently reported in a focal region of the anterior cingulate cortex (ACC) and in the dorsolateral prefrontal cortex (DLPFC). Multiple-episode patients showed decreased grey matter in the dorsomedial prefrontal cortex (DMPFC), with first-episode depression (FED) patients showing greater reductions in grey matter volume in the amygdala. It would be interesting to investigate further this correlation with cognition.

Rock et al., 2014 confirmed cognitive deficits as an important treatment target in a meta-analysis (Rock et al., 2014). Their review included only one extensive, computerised, language-independent, neurocognitive test battery, the Cambridge Neuropsychological Test Automated Battery (CANTAB), overcoming limitations with non-standardised effect measures, and ensuring consistent testing across several domains, focusing on executive function, memory, attention, and reaction time. 784 symptomatic MDD patients (494 female, 290 male) and 168 remitted patients (54 female, 114 male) were included. Significant deficits were confirmed during acute episodes of MDD that persisted in remission, particularly executive function and attention.

The reviewed evidence makes it clear that cognitive deficits are prevalent in both acute and remitted depression and pose significant detriment to quality of life in patients.

\subsubsection{Cognit ive deficit $s$ in first-episode depression}

A meta-analysis by Lee et al., 2012 evaluated neuropsychological deficits during a first episode of depression (FED; Lee et al., 2012). Previously linked to increased relapse rates and recurrent episodes of MDD, the role of cognitive dysfunction in treatment resistance and 
remission clearly provides an opportunity for early intervention. This meta-analysis extended findings supporting the potential for early identification of cognitive deficits in FED. 13 studie s were reviewed, providing data from 644 FED patients. Cognitive domains tested were consistent with earlier studies, with several measures investigated (Table 1). Cognitive function was found to be significantly worse in first-episode versus recurrent-episode patients, with medium effect sizes measured in six of eight domains, excluding working memory and verbal learning. In terms of treatment effects, antidepressants were associated with increased cognitive flexibility, but also reduced memory and verbal learning. Many samples were limited by poor control for treatment effect, typically treatment by TCAs or typical antipsychotics, and several study results were limited by small sample size as well as poor reporting of clinical characteristics.

More recently, Vicent-Gil et al., 2018 reviewed the role of cognitive predictors in a trial comparing 50 FED patients (30 female, 20 male) with 40 healthy controls (Vicent-Gil et al., 2018). Cognitive measures were assessed at baseline and at 12-month follow-up using an assembled neurocognitive battery (Table 1), which included testing across executive function, language, verbal memory, and processing speed domains. In terms of medication, patients were either antidepressant-naïve or taking equivalent regimes of escitalopram, citalopram or fluoxetine for less than two weeks before the trial started. In contrast to previous findings, FED patients presented with only moderate cognitive impairments when considered as a whole, in comparison to healthy controls at follow-up. Perhaps most interesting is that two clinical subgroups emerged from the FED sample results: 37 'cognitively preserved' patients with no measured cognitive deficits, and 13 'cognitively impaired' patients with dysfunction measured across most cognitive domains. It would seem that cognitive deficits are not homogenous, and that their presentation offers one method by which to stratify patients early in treatment; additionally, it is possible that these 'cognitively preserved' patients may recover more quickly than those with impairments. From this sample, $26 \%$ of FED patients, comprising those within the 'cognitively impaired' cluster, displayed significant impairments in working memory, attention, and verbal memory domains. In all FED patients, verbal memory predicted baseline symptoms, whereas executive function and language predicted 12 -month symptom severity. Poorer cognitive ability also predicted greater symptom severity and poorer outcomes at 
baseline and 12-month follow-up, as also seen in schizophrenia, indicating that early cognitive assessment at disease onset may help support improved outcomes for patients.

The presentation of cognitive deficits is not homogenous in FED patients, despite shared diagnoses and clinical similarities. The influence of cognitive deficits and differences in these at depression onset indicate an apparent need for earlier detection and treatment of these deficits, and for individualised treatment in patient subgroups, e.g. cognitive remediation plus antidepressant therapy in those FED patients with cognitive dysfunction.

\subsubsection{Cognitive dy sfunction and psychosocial funct ioning}

Given that cognitive deficits persist beyond acute MDEs and into remission, it follows that they can then present significant barriers to functional recovery. Cognitive impairment may thus lead to depression relapse and poorlong-term prognosis, and compound existing difficulties with social and global function, as well as employment and workplace productivity.

Knight et al., 2018 sought to define the relationship between impairments in specific cognitive domains and psychosocial functioning in MDD patients (Knight et al., 2018). Results of the Cognitive Function and Mood Study (CoFaM-S) were analysed, in which 182 remitted MDD patients (107 female, 75 male) underwent cognitive testing using three objective batteries: RBANS, Colorado Assessment Tests, and Psychology Experiment Building Language. In order to assess psychosocial ability, the Functioning Assessment Short Test (FAST), a clinician rated interview was used that assesses six functional domains: autonomy, occupational functioning, cognitive functioning, financial issues, leisure time, and interpersonal relationships. In comparison with 110 healthy controls, executive function was concluded to have the most significant effect on psychosocial impairment, workplace functioning, and social cognition in remitted patients.

Knight and Baune, 2018 reviewed the influence of specific executive subdomains on psychosocial functioning (Knight \& Baune, 2018). Given that executive function includes several subdomains, including decision making, set-shifting, forward planning, problem solving, working memory, cognitive flexibility, cognitive updating, and inhibition, it follows that executive dysfunction can have significant negative impact upon psychosocial functioning. A sample of 142 patients ( 88 females, 54 males) were analysed from the CoFaM- 
S study, of which 31 had current depression, 52 remitted depression, and 59 were healthy controls. FAST was used to assess psychosocial function, and executive function was measured using a collection of established tests, including the Stroop task, Tower of London, and Berg's Card Sorting Test. Executive subdomains were measured by individual performance in different tasks; forward planning, for example, was gauged using the total moves in the Tower of London task. Within each clinical subgroup, the relationship between executive subdomains and psychosocial functioning was significant. In currently depressed patients, forward planning correlated most significantly with overall psychosocial dysfunctio $n$, as well as issues with autonomy, subjective cognition, leisure time, and interpersonal relationships. In remitted patients, however, no one subdomain was identified in sole relation to dysfunction. The cognitive updating subdomain of executive function was found to be negatively associated with reduced psychosocial and occupational functioning.

It is possible that specific testing of forward planning may be a better indicator of functional ability in acute MDD patients. Given that both acute and remitted MDD patients displayed differential executive function relationships, the importance of patient stratification is again highlighted. Lack of separation between the two clinical subgroups may in part be the reason for previous research discrepancies.

Cambridge et al., 2018 performed a systematic review of 28 studies, yielding 6811 adult and elderly MDD patients, in order to identify the strongest predictors of psychosocial functioning outcomes, their longitudinal effects, and any clinical and demographical features that might influence this relationship (Cambridge et al., 2018). Across 23 cross-sectional studies ( $N=5768)$ and 5 longitudinal studies $(N=1043)$, performance-based $(N=5)$ or subjective $(\mathrm{N}=24)$ assessments measured psychosocial function, with 22 studies concluding a significant relationship between cognitive deficits and psychosocial dysfunction. Within the cross-sectional analyses, 'executive function, attention, memory and global cognition' domains were significantly associated with psychosocial impairments in 'quality of life, social, occupational, and global functioning', Subjective assessments reported that global co gnition and executive function had the greatest influence upon daily functioning impairments, whereas objective assessments highlighted the role of executive function in daily functioning, as well as verbal fluency and attention in social skill dysfunction. Within the longitudinal analyses, two studies 
reported that verbal learning, prospective memory and again, executive function were the strongest predictors of functional outcomes at 3-and 6-month follow-up, with the majority of studies concluding that executive function and attention were key domains affecting long-term psychosocial outcomes. Older age and depression severity were also recognised as compounding factors on longitudinal psychosocial outcomes, increasing both the 'susceptibility and magnitude' of these deficits.

Taken together, these findings show that cognitive impairments result in both shortand long-term psychosocial dysfunction. Executive functioning in particular, alongside attention and memory, are most significantly related to poorer functional outcomes. Looking towards the future, further insight into forward planning dysfunction and the positive role of cognitive updating in remission may be key to developing future treatments, as well as targeting the domains highlighted as most significantly related to functional outcomes.

\subsubsection{Improved detection and measurement of cognit ive deficits}

Evidence has established that cognitive deficits are prevalent in acute and remitted depression patients. FED patients also present with cognitive impairment, although, despite shared diagnoses and clinical similarities, these impairments occur at varying degrees of severity. The urgent need for earlier detection and treatment of these deficits is apparent, together with assessment of patients on an individual, rather than collective, level.

Table 1 illustrates the disordered state of current cognitive assessments, where many studies have been limited by extensive, long, and potentially exhausting neurocognitive assessments. With no consensus on which domain is measured by each test, many studies have used different tasks and different formats to measure the same domain. For example, the TMT Part B test is considered by some as a measure of executive function, and by others attentional switching. Where some studies have used single batteries, such as CANTAB or RBANS, others have formulated their smaller batteries using combinations of tests, leading to inconsistent analyses and comparison difficulties. A standardised test battery is critical in order to improve future studies, as attempted by the Measurement and Treatment Research to Improve Cognition in Schizophrenia (MATRICS) battery in schizophrenia (Marder \& Fenton, 2004). 
Most recently, Baune et al., 2018 highlighted the THINC-it tool as one method to secure more valid assessment of cognitive function in patients (Baune et al., 2018). In comparison the Mini Mental State Examination (MMSE) or RBANS, the THINC-it assessment is a more affordable, accessible and practical screening tool intended for use during routine clinical assessment. It is available in the format of a rapid, accessible, and language-independent application optimised for several operating systems. Risk factors for relapse and recurrence of depression include residual depression symptoms after treatment, longer duration, and greater severity of disease (Buckman et al., 2018). Earlier detection of cognitive deficits would be a good use of resources and provide long-term benefit to patients. Although frequent re-testing may be valuable for detection, this may be limited by practice effects.

Using objective and subjective measures such as the Perceived Deficits Questionnaire for Depression-5-item (PDQ-5), THINC-it may relieve the long-term impact of poor cognitive function by better detection of these deficits, as well as by facilitating earlier identification and treatment. This is in keeping with findings that cognitive deficits are possible early identification targets, and that cognitive measures may be predictive of future psychosocial impairments, particularly as a means of patient stratification (Lee et al., 2012; Cha et al., 2017). Although it does not predict treatment response, THINC-it could be used by healthcare professionals and patients to measure treatment efficacy and on-going cognitive function, either at home or in clinics. Additionally, the tool may be ideally suited for uncovering signs of potential cognitive dysfunction in high-risk patients before symptoms appear, although conclusive evidence has yet to be found regarding whether cognitive deficits occur before a diagnosis of depression as for psychosis (Keefe, 2014).

McIntyre et al., 2017 validated the THINC-it tool in 90 moderate to severely depressed MDD patients (51 female, 39 male) (Mclntyre et al., 2017a). A significant difference was reported between MDD patients and controls, confirming the existence of cognitive deficits in patients. Although the 'gold standard' for neurocognitive testing would be an extensive battery like CANTAB, the THINC-it application is free, simple to use, downloadable to computers, mobile phones or tablets, and can be self-administered. The THINC-it tool is shorter than traditional batteries, with MDD patients averaging at around 10-15 minutes for completion. Assessing the same cohort, Cha et al., 2017 reported THINC-it as a successful 
screening measure for cognitive impairment and psychosocial functioning. In the MDD group, loss of more economic days and reduced workplace productivity were significantly associated with greater depression severity, cognitive deficits, and psychosocial impairment. THINC-it detected subjective, patient-reported cognitive function, supplementing objective measures and helping to identify psychosocial dysfunction independent of depression severity scores.

THINC-it is not extensive enough to replace the larger test batteries used in clinical trials, and a more uniform neurocognitive battery remains an unmet research need. Similar to 'Cognigram', an electronic version of the Cogstate Brief Battery (CBB) which is shorter than MATRICS and used in schizophrenia, the accessible, computerised, and language-independent nature of THINC-it does still, however, present several advantages for screening and detection purposes (Cogstate, 2014).

As demonstrated by several studies thus far, a diagnosis of depression is insufficient evidence to confirm either the presence or absence of cognitive impairment. In 262 unmedicated MDD patients (161 female, 101 male), Keilp et al., 2018 confirmed that cognitive performance was not significantly associated with the scores on standard depression severity measures often employed in clinical trials, using the 24-item Hamilton Depression Rating Scale (HDRS) and Beck Depression Inventory (BDI) (Keilp et al., 2018). Cognitive assessment was carried out using a 10-test battery, including Choice Reaction Time (CRT), Wechsler Adult Intelligence Scale (WAIS-III), Continuous Performance Test (CPT), Stroop test, Selective Reminding Test (SRT), Wisconsin Card Sorting Test (WCST), and Go-No-Go tests. Neither subjective cognitive complaints, as measured by the Cognitive Failures Questionnaire (CFQ-25), nor results from depression measures were significantly linked to cognitive performance. Patients meeting certain clinical criteria, however, such as for melancholia or history of substance abuse, showed stronger correlation between depression severity and cognitive impairment than others. In addition, late-onset patients also presented with slower reaction time and reasoning speed, confirming once again the heterogenous nature of cognitive deficits. Although the CFQ-25 should capture subjective cognitive complaints missed by severity scores and objective battery testing, Keilp et al., 2018 noted that these scores were more indicative of mood, rather than neurocognitive ability. This may challenge the inclusion of subjective measures to broaden cognitive assessment in trials, or at the very least indicate that 
such measures and their subsequent results should be interpreted with caution. Cognitive impairment is thus inadequately captured by classic depression rating scales. As the majority of studies use these scores for inclusion and screening, this is a cause for concern. Furthermore, it underscores the need for more accurate, sensitive cognitive screening tools and test batteries.

Ballard at al., 2018 assessed common depression rating scales used in clinical ketamine trials with 76 MDD and 43 bipolar patients (Ballard et al., 2018). Ratings from the BDI, Snaith-Hamilton Pleasure Rating Scale (SHAPS), HAM-D, and MADRS were used to identify the range of symptoms reported. In order to accurately capture the heterogeneity of depression, eight symptom domains were proposed instead of total measure scores from individual ratings, including: depressed mood, tension, negative cognition, impaired sleep, suicidal thoughts, reduced appetite, anhedonia, and amotivation. These unidimensional ratings may be more representative of the range of symptoms experienced by depression patients, thus helping to pinpoint their underlying pathophysiology and consequent treatment options.

In essence, earlier detection and prevention of cognitive deficits in an "at risk" population is necessary to improve functional outcomes. Newly validated tools such as THINCit may make detection of these deficits easier. Across the majority of clinical trials, however, the measurement of cognitive impairment remains inadequate. This disorganised state of neurocognitive assessment would be best alleviated by the development of one standardised test battery, which should be sensitive and accurate enough to detect varying and highly individual degrees of cognitive impairment in depressed patients.

\subsection{Evaluation of antidepressant therapy on cognition}

Cognitive impairment has been established as a significant and thus far untreated clinical need in MDD patients, and it is important to consider effects of existing antidepressant therapies on cognitive function.

In this review, the effects of 'traditional antidepressants' such as SSRIs sertraline, fluoxetine, escitalopram, paroxetine, citalopram; SNRIs duloxetine, venlafaxine, desvenlafaxine; TCAs nortriptyline and dothiepin, and the norepinephrine-dopamine reuptake inhibitor (NDRI) bupropion will be discussed in relation to their effects on cognition, together with the novel multimodal serotonin modulator vortioxetine and NMDA receptor antagonist ketamine. As 
recent literature has discussed antidepressant effects on cognition, this review intends to collate these findings and discuss additional contributions (Keefe et al., 2014; Rosenblat et al., 2015).

\subsubsection{Placebo cont rolled trials of t radit ional ant idepressant $s$ in cognit ive impairment}

In placebo-controlled trials conducted to date (Table 2), the SSRI citalopram and SNRIs duloxetine, desvenlafaxine, and venlafaxine show mixed results. Testing verbal learning, memory, attention, and executive function in an 8-week double-blind trial in 207 elderly MDD patients, Raskin et al., 2007 described significant improvements with duloxetine $60 \mathrm{mg}$ on verbal learning and recall (Raskin et al., 2007). Venlafaxine 75-150mg also showed positive results, with Tian et al., 2016 reporting selective improvements in executive control of attention and MDD symptoms after 6 weeks in the Attention Network Test, although in only 34 patients (Tian et al., 2016). With desvenlafaxine $50 \mathrm{mg}$, Reddy et al., 2016 used the cognitive drug research (CDR) system to show significant working memory improvements over 12 weeks (Reddy et al., 2016). This positive effect may be a direct result of serotonin and noradrenaline reuptake inhibition, improving symptomatology and cognition, although the small sample size of 81 is limiting. Interestingly, Tian et al., 2016 reported that executive control and depression symptom improvement were not correlated, indicating that these effects may potentially occurvia different mechanisms.

Regarding the SSRI citalopram, mixed results were found by Culang et al., 2009. After 8 weeks, 20-40mg citalopram non-responders reported impaired verbal learning and psychomotor speed, suggesting that treatment may wors en cognition in patients nonresponsive to medication (Culang et al., 2009). Although citalopram responders improved in visuospatial functioning, this effect was no greater than those receiving placebo; improvements in psychomotor speed were also no more significant than those seen in placebo responders or non-responders. These findings suggest that response status may be an indicator of potential negative treatment effects on cognition, and that citalopram presented small but non-significant improvements when compared to placebo.

Taken in combination, these data suggest that SNRIs could potentially improve memory and verbal learning, though small sample sizes and elderly populations limit current 
analysis. Although selective improvements have been reported with SNRIs, Table 2 highlights a lack of consistency in the cognitive measures used, compounding problems with generalisability. Further research with larger sample sizes is warranted before firm conclusions can be made, ideally using a standardised test battery. As it is yet unclear whether the positive effects of SNRIs on cognition occurs via improvement of depression symptoms, or by a secondary independent mechanism, more research is clearly required.

\subsubsection{Act ive comparat or trials of t radit ional ant idepressant $s$ in cognit ive impairment}

Within active comparator trials (Table 3), the SSRIs sertraline, fluoxetine, escitalopram, SNRIs venlafaxine and duloxetine; TCAs nortriptyline and dothiepin, and NDRI bupropion were compared for effects on cognition.

Doraiswamy et al., 2003 and Culang-Reinleib et al., 2012 both reported cognitive improvement with sertraline $50-200 \mathrm{mg}$. Compared with nortriptyline $25 \mathrm{mg}$ and fluoxetine 20mg, Doraiswamy et al., 2003 found that sertraline led to the greatest improvements in depression, verbal learning (SLT) and visual tracking and motor performance (DDST) (Doraiswamy et al., 2003). In 440 patients, baseline cognitive impairments correlated with greater baseline depression severity and older age, and those with greater cognitive deficits also saw greater magnitudes of improvement. Directly comparing with nortriptyline $1 \mathrm{mg} / \mathrm{lkg}$, Culang-Reinleib et al., 2012 reported that sertraline patients showed significant improvement in verbal learning, and more so than nortriptyline patients, who showed no improvements (Culang-Reinlieb et al., 2012). Sertraline also improved memory in non-responders, indicating that effects on cognition may be independent of those on depression symptomatology, consistent with previous suggestions by Tian et al., 2016. Given the small sample size $(\mathrm{N}=33)$ and lack of placebo control, further replication studies are warranted. Neurocognitive testing could also have been more rigorous, as domain-specific results and analyses were limited.

Trials by Herrera-Guzman et al., 2009 and 2010, treated 73 patients with either escitalopram $10 \mathrm{mg} /$ day (SSRI) or duloxetine $60 \mathrm{mg} /$ day (SNRI) for 24 weeks, after which they were assessed for a further 24 weeks following remission (Herrera-Guzman et al., 2009; Herrera-Guzman et al., 2010). Both treatments improved episodic memory, with smaller 
improvements also in working memory, processing speed, and motor performance. Upon further analysis, duloxetine had greater beneficial effect on episodic memory than escitalopram, with the latter group recording lowerverbal and visual memory scores at the 24 week follow up assessment. At this time-point, it was also confirmed that cognitive deficits persisted beyond the remission phase, and that the SNRI was still superior in improving episodic and working memory. Different results to previous studies may be due in part to more robust study design, i.e. long duration of treatment with a long follow-up period, and more representative sample population, with a mean age of 33 years and extensive application of the CANTAB battery, consisting of individual tests listed in Table 3.

Trick et al., 2004 also investigated the effects of SNRIs, trialling venlafaxine $75 \mathrm{mg}$ against the TCA dothiepin $75 \mathrm{mg}$ in 88 elderly patients (Trick et al., 2004). Although both treatments achieved therapeutic effects and clinical efficacy, venlafaxine showed a modest improvement in cognition as measured by the Critical Flicker Fusion (CFF) test, indicating CNS arousal. Conversely, dothiepin was associated with decreased CFF performance, linked potentially to its anticholinergic and antihistaminergic pharmacology.

The NDRI bupropion (150-300 and 150-450mg respectively) was tested in two trials by Soczynska et al., 2014 and Gorlyn et al., 2015, comparing efficacy against the SSRIs escitalopram 10-20mg and paroxetine 25-50mg. In 41 MDD patients, Soczynska et al., 2014 found that both bupropion $X L$ and escitalopram significantly improved verbal and non-verbal learning and memory, global function, and work productivity (Soczynska et al., 2014). Gorlyn et al., 2015 concluded that bupropion and paroxetine improved neurocognitive performance across psychomotor, attention, memory and working memory domains in 67 MDD patients with past or current suicidal ideations (Gorlyn et al., 2015). Paroxetine had a slightly greater improvement in psychomotor speed. Although no significant superiority was reported between the two studies, this may be due to the reduced statistical power of small sample sizes. Depression symptom improvement was not associated with improved cognition, once again suggesting that these two effects may occur via independent mechanisms. Gorlyn et al., 2015 also noted that verbal memory improvements correlated with reduced suicidal ideation.

Shilyansky et al., 2016 trialled 1008 MDD patients with escitalopram (SSRI), sertraline (SSRI) or venlafaxine-XR (SNRI), with average doses of $12.3 \mathrm{mg}, 61.1 \mathrm{mg}$ and $83.4 \mathrm{mg}$ per day 
respectively (Shilyansky et al., 2016). The IntegNeuro battery (listed in Table 3) was used to test 9 cognitive domains: attention, response inhibition, verbal memory, executive function, cognitive flexibility, working memory, decision speed, information processing, and motor coordination. Both individual and group level cognition was assessed to account for possible change in cognitive ability across different subgroups. Participants had not been receiving medication before the trial, and the average age was 37.8 years.

No significant improvements were measured in the majority of domains at trial completion, although some improvement was noted in executive function and cognitive flexibility. Across the other five domains, those with clinical remission saw an equal lack of improvement as patients with active MDD. Results reported that only $4.5 \%$ of patients had impairment resolution after treatment, with generally no more than two domains showing a significant effect in any one person. The group that saw this improvement were those with later disease onset. No one antidepressant was recorded as superior in any single patient group, and no significant results were reported regarding sex differences.

\subsubsection{Conclusion and limit at ions of $t$ raditional ant idepressant $t$ rials}

In placebo-controlled trials, the SNRIs duloxetine, desvenlafaxine and venlafaxine appeared to be superior to citalopram in terms of cognitive benefit. Yet in terms of activecomparator trials, the results are more complex. Where sertraline has been associated with greater improvements compared to fluoxetine or nortriptyline, duloxetine and venlafaxine have also been reported as superior to escitalopram and dothiepin respectively, and detrimental cognitive effects were reported with dothiepin. Neither escitalopram, sertraline, nor venlafaxine provided significant improvements in cognition. In summary, traditional antidepressants have varying intra- and inter- class-dependent effects on cognition, and no particular antidepressant (or class) has been found to have consistently superior effects on cognition.

It is of interest to note some pharmacological findings. Post treatment with venlafaxine, Tian et al., 2016 reported that improved executive control and depression severity were not correlated, indicating that these are likely underpinned by different mechanisms. A selective effect to improve the executive control of attention, often manifesting in patients as impulsivity, was suggested to be due to increasing DA concentration in frontal, limbic, and 
parietal areas. This extends suggestions by Herrera-Guzman et al., 2009 and 2010, where superior action of SNRIs on recovering episodic and working memory was linked to $5-\mathrm{HT}$ and NE stimulating DA release in the DPFLC, driving neural circuits in conjunction with the thalamus and basal ganglia (Herrera-Guzman et al., 2009; Herrera-Guzman et al., 2010). In terms of TCAs, Trick et al., 2004 indicated that cognitive impairment may be associated with the sedative effects of dothiepin, leading to more pronounced difficulties with cognitive and psychomotor functions, particularly in the elderly. Culang-Rienleib 2012 suggested that lack of verbal learning improvements in nortriptyline responders may be due to anticholinergic effects impairing memory. Further research into the advantageous and disadvantageous effects of SNRIs and TCAs would be valuable; such findings could provide evidence for treatment adjustments in existing populations, particularly in the elderly, in order to preserve cognitive function. In addition, further clarity is required as to whether antidepressants can improve cognition independent of their effect on symptom severity.

In terms of limitations, generalisability was questionable due to small samples consisting mostly of elderly patients. Participants ranged from mild to severely depressed, making it difficult to distinguish whether cognitive impairment changed due to treatment, or whether it remained impaired due to disease severity. Cognitive testing varied considerably, as outlined in Tables 2 and 3, and the variety of assessments and their interpretation makes true comparison difficult. The Controlled Oral Word Association Test (COWAT), for example, was cited as a test of verbal fluency, processing speed, or executive function, making the likelihood of methodological inconsistences high. These results provide further research setbacks, and confirm the need for standardised cognitive test batteries for MDD.

Despite regulatory and research advances recognising cognition as an important target, treatment advances are still unsatisfactory due to the 'patchwork set of methods' used in studies, where methodological difficulties and lack of longitudinal studies are confounding results across the field (Keefe, 2016). This, togetherwith unrepresentative patient ages, variable study designs, lack of gender in the analysis and lack of follow-up data, are limitations that must be overcome.

\subsubsection{Novel ant idepressant $s$ in cognit ive impairment}


Vortioxetine is a novel antidepressant with unique pharmacology, working as a multimodal serotonin inhibitor at serotonin transporters (SERTs) to inhibit 5-HT reuptake, displaying 5-HT3, 5-HT1D and 5-HT7 receptorantagonism, 5-HT1A receptor agonism and partial 5-HT1B receptoragonism (Sanchez et al., 2015). Vortioxetine's 5-HT1A receptor agonist effect has been suggested to inhibit GABA release, promoting secondary release of DA, NA, histamine (HA) and acetylcholine (Ach) in the hippocampus and PFC (Salagre et al., 2018). Ketamine, a non-competitive NDMA receptor antagonist, has been found to be effective in reducing suicidality and depressive symptoms in TRD, and a form of ketamine, esketamine has very recently been licensed by the Food and Drug Administration (FDA) for depression. The evidence for these two treatments will be reviewed in this section (Table 4).

With good tolerability and broad antidepressant effect, the potential of vortioxetine to improve cognitive function is an exciting prospect. In an 8-week randomised control, active reference study, Katona et al., 2012 trialled vortioxetine 5mg (Lu AA21004) and duloxetine $60 \mathrm{mg}$ in 453 elderly patients (Katona et al., 2012). Although both treatments were efficacious in improving depression symptoms and Rey Auditory Verbal Learning Test (RAVLT) scores, vortioxetine significantly improved Digit Symbol Substitution Test (DSST) performance, suggesting efficacy beyond the verbal learning and memory improvements reported previously with duloxetine by Katona et al., 2012 and Raskin et al., 2007. Vortioxetine led to significant improvements in processing speed, verbal learning, and recall domains, and given that performance on the DSST requires executive function, this may also have been improved. Over two-thirds of vortioxetine's effect on cognition was due to direct treatment effect, and not by indirect improvement of symptom severity as with duloxetine.

Mahableshwarkar et al., 2015 trialled vortioxetine 10-20mg alongside duloxetine $60 \mathrm{mg}$ in an 8-week randomised, placebo-controlled, and active-reference study of 602 MDD patients with self-reported cognitive dysfunction (Mahableshwarkar et al., 2015). The neurocognitive battery employed several objective cognitive measures, as listed in Table 5, together with the PDQ and Cognitive and Physical Functioning Questionnaire (CPFQ) as subjective, patient-reported measures. Where both duloxetine and vortioxetine significantly improved attention/concentration and planning/organization PDQ scores, only vortioxetine significantly improved DSST and TMT-B performance, indicating restored executive function and 
quicker cognitive processing speed. Duloxetine did not separate from placebo on DSST performance, and its positive effects on PDQ scores were attributed to improved depression symptoms only, rather than specific pro-cognitive action. Although inclusion criteria only required patient-reported measures of cognition, it was suggested that this reporting system may be more applicable to clinical practice; it will be important, therefore, for future trials to investigate objectively measured deficits at inclusion for comparison.

In an 8-week, randomized, placebo-controlled study by McIntyre et al., 2014, vortioxetine 10-20mg was trialled in 602 MDD patients (Mclntyre et al., 2014). Although RAVLT and DSST tests were again used, six other tests, as listed in Table 4, provided a more detailed composite score. Significant improvement was reported in objective measures of executive function, attention, processing speed, learning and memory, with the subjective, patientreported PDQ also indicating improvement in memory, concentration, and planning/organization. It is worth noting that vortioxetine's improvement of cognition was due to both direct and indirect therapeutic effects. When given at $20 \mathrm{mg}$, vortioxetine showed a more significant improvement in MADRS severity scores disparate from the improvement in cognition, suggesting that these effects do in fact occur by separate mechanisms.

Harrison et al., 2016 investigated which specific domains vortioxetine improves (Harrison et al., 2016). In an 8-week, randomised, placebo-controlled trial, vortioxetine $10 \mathrm{mg}$ $20 \mathrm{mg}$ was administered to 602 MDD patients, with the DSST used as a primary assessment to analyse effect sizes on executive function, processing speed/attention, and memory. In keeping with findings by Katona et al., 2012 and Mahableshwarkar et al., 2015, vortioxetine again led to improved DSST performance. Harrison et al., 2016 did emphasise that this change does not necessarily mean improvement on any one specific domain; rather, it requires integration of several, more broad cognitive skills engaged by the DSST, which were reflected by changes in the other individual neurocognitive tasks included, noted in Table 4.

Smith et al., 2018 conducted a placebo-controlled, randomised fMRI neuroimaging trial in 96 remitted MDD patients and healthy controls, who were administered vortioxetine $20 \mathrm{mg}$ or placebo over 2 weeks to assess neural and cognitive function (Smith et al., 2018). In previous remitted and active MDD patient studies, blood-oxygen-level-dependent (BOLD) signal activation has been shown to increase and maintain hyperactive response during task 
performances. When fMRI was applied during the N-back working memory task, vortioxetine showed reduced BOLD signal activation in the dIPFC, left hippocampus, and temporal-parietal areas across both treatment groups, and also led to improved TMT-A performance and PDQ scores. Vortioxetine may thus reduce effort and encourage more efficient recruitment of the default mode network (DMN) and task-positive networks during working memory tasks. This could explain the direct and independent effect of vortioxetine on cognition, specifically on executive function and working memory. These results however, remain limited by the short trial length and lack of objective deficits reported by the remitted sample at the start of the trial.

In a randomised, double-blind, active-comparator study, Vieta et al., 2018 explored the effects of vortioxetine or escitalopram 10-20mg on cognitive function and depression severity in 99 MDD patients with inadequate response to 6 weeks of SSRI or SNRI treatment (Vieta et al., 2018). The DSST was applied as a primary assessment of cognition, with the UCSD Performance-based Skills Assessment-Brief (UPSA-B) used to ascertain functional capacity. Secondary cognition assessments were obtained using the score in Table 4. Although both treatment groups reported improved DSST and UPSA-B performance with no significant differences, improvements in seven cognitive testing domains favoured vortioxetine, with the exception of the TMT-A and SRT. These results again confirm the efficacy of vortioxetine in improving cognitive function and ameliorating depression symptoms, although comparison with escitalopram as an active treatment is difficult without a larger-scale replication trial.

Previous findings regarding ketamine (Shiroma et al., 2014; Yoosefi et al., 2014; Murrough et al., 2015) reported mixed effects on cognition in three small-scale trials, with suggestions that ketamine may improve visual and working memory, potentially due to symptom improvement rather than direct pro-cognitive effects. Extending this research, Chen et al., 2018 trialled doses of 0.2 and $0.5 \mathrm{mg} / \mathrm{kg}$ of ketamine against placebo saline infusion in 71 patients with TRD (Chen et al., 2018). Using a cognitive battery of two tests (Table 4), they found that, while $0.2 \mathrm{mg} / \mathrm{kg}$ ketamine did not impair cognitive function, $0.5 \mathrm{mg} / \mathrm{kg}$ improved attention and response control in a go/no-go task. The negative correlation with depression symptoms may suggest that it was the antidepressant effect that improved cognition. 
In conclusion, vortioxetine is a viable antidepressant with cognitive enhancing effects across several domains. More longitudinal replication and active-comparator trials with current first-line therapies, such as SSRIs or SNRIs, are still required, as for ketamine, particularly with a view to developing therapies for the treatment-resistant patients with cognitive deficits. Two ketamine trials are currently undergoing recruitment (ClinicalTrials.gov, NCT02659085; NCT01881763). Further investigation into the pro-cognitive and antidepressant mechanisms of vortioxetine is also important, particularly in acutely depressed patients.

\subsection{Evaluation of novel trea tments on cognitive impairment}

Interest in cognitive therapies has grown considerably over the last two decades. Despite an abundance of exciting opportunities, recent literature has identified numerous limitations, including a lack of standardisation in trial designs, heterogeneous samples, and conflicting results (Carvalho et al., 2014; Bortolato et al., 2014; Sole et al., 2015; Salagre et al., 2017; Miskowiak et al., 2016).

This part of our review will briefly update established findings, evaluate the most recent contributions to the field, and identify potential patient stratification techniques. Although recent reviews of physical, physiological, and biological therapies have been promising, analysis of these interventions is beyond the scope of this review. We refer the reader to studies on deep brain stimulation (Bergfeld et al., 2017; Kubu et al., 2017), repetitive transcranial magnetic stimulation (Noda et al., 2018), transcranial direct current stimulation, (Salehinejad et al., 2017; Martin et al., 2018), cognitive remediation (Bowie et al., 2013; Trapp et al., 2016; Motter et al., 2016), exercise (Brondino et al., 2017; Buschert et al., 2018) and other physical therapies (Greer et al., 2017; Listunova et al., 2018).

Table 5 outlines the main study characteristics for novel therapies used for cognitive impairment in recent trials, generally as augmentation with concomitant antidepressant treatment, and only those with cognitive outcomes have been included.

\subsubsection{St imulant s}

Stimulants with potential pro-cognitive effects include methylphenidate, modafinil, lisdexamfetamine (LDX), and nicotine (DeBattista et al., 2004; Madhoo et al., 2014; Lavretsky et al., 2015). In a proof-of-concept study, Kaser et al., 2017 (Table 6) reported that modafinil 
$200 \mathrm{mg} /$ day significantly improved episodic and working memory in 60 remitted patients, whereas attention and planning saw no improvement as measured by the CANTAB battery (Kaser et al., 2017). A current placebo-controlled trial of 50 patients should provide further insight into the efficacy of modafinil 200mg/day on cognition in rMDD (NCT03620253).

To our knowledge, no new results have yet been published using methylphenidate and LDX for cognition in MDD. Although LDX augmentation has been of recent interest in MDD, non-significant effects have been reported on depression severity (Richards et al., 2017, Giacobbe et al., 2018). The benefits of LDX may become more apparent when trialled with cognition as a primary outcome, as in a current trial (NCT01148979). McIntyre et al., 2017 has also emphasised targeting psychopathologies such cognitive impairment with stimulants, rather than antidepressant effect (McIntyre et al., 2017b). Although psychostimulants could ameliorate cognitive impairments in MDD, this cannot be confirmed without cognition-specific studies with consistent methodologies, and neuroimaging to confirm target-engagement.

Nicotine, a nicotinic acetylcholine receptor (nAChR) agonist, may have efficacy to improve cognition in MDD. Gandelman et al., 2018 reported mixed effects of nicotine in latelife depression (LLD) in cognitive tests (Gandelman et al., 2018). Where CPT and Rapid Visual Information Processing (RVP) tests were administered, nicotine improved sustained attention. This was not found with the Attention Network Task (ANT), with additional inconsistent results regarding long-term and working memory, potentially mediated via improvements in attention. Currently, a transdermal nicotine $3.5 \mathrm{mg}-21 \mathrm{mg}$ patch is being trialled (NCT02816138). The recommendation of Gandelman et al., 2018 is clear: to conduct a 'randomized, blinded, placebo-controlled trial of transdermal nicotine in non-smokers with LLD', with 'dual outcomes for both depression severity and cognition', with measures to assess 'attentional performance, episodic and working memory, and executive function'. The outcome of this trial will be important for future therapeutic strategies.

\subsubsection{Ant i-inflammatory and ant i-oxidant therapies}

Anti-inflammatory and anti-oxidant therapies with potential pro-cognitive effects include S-adenosylmethionine (SAMe), omega-3, Erythropoietin (EPO), and metformin. 
SAMe is an essential component in human metabolism and biochemistry, including neurotransmitters such as DA, NE and 5-HT (Carvalho et al., 2014). In an augmentation trial of 66 SSRI non-responders with MDD, SAMe $800 \mathrm{mg} /$ day showed some positive effects; the subjective CPFQ measure showed improved recall and word finding, but no significant change in any of the other five cognitive domains tested (Levkovitz et al., 2012).

A systematic review by De Berardis et al., 2016 concluded SAMe to be a welltolerated and potential therapeutic option in MDD and TRD patients (De Berardis et al., 2016). Where those with mild symptoms could benefit from SAMe monotherapy before antidepressant initiation, treatment-resistant populations may also benefit from add-on therapy. More recently, Sarris et al., 2018 conducted an 8-week placebo-controlled RCT in 107 non-remitted MDD patients, where an add-on of $800 \mathrm{mg} /$ day SAMe was no superior in effect to placebo (Sarris et al., 2018). No biomarkers significantly correlated with SAMe response. High placebo response and lower dosing of SAMe should, however, be noted in this study, as well as the moderate to severe inclusion criteria. Given that cognitive function has been shown to decline with increasing disease severity, it would be interesting to trial the pro-cognitive ability of SAMe in mildly symptomatic patients, as this could be a key early time-point for future interventions, and an opportunity missed by previous studies.

Omega-3 polyunsaturated fatty acids (PUFAs), including $\alpha$-linolenic acid, docosahexaenoic acid and eicosapentaenoic acid, have been shown to inhibit the microglial inflammatory response and exhibit a neuroprotective effect in animal models. In 190 MDD patients, supplementation with $1.5 \mathrm{~g} /$ day $\mathrm{n}-3$ long-chain PUFA led to no significant improvement in cognition (Rogers et al., 2008). In a trial of 36 remitted patients, $2.3 \mathrm{~g}$ omega-3 fatty acid led to small improvements in emotional decision-making/information processing as measured by the AGN and Facial Expression Recognition task (Antypa et al., 2012). Currently, two trials with cognitive outcome measures are investigating fish oil supplementation in 120 MDD and 89 LLD patients (NCT03295708; NCT01235533).

A 12-week, randomised, placebo-controlled study by Jahangard et al., 2018 investigated omega-3 supplementation alongside sertraline $50-200 \mathrm{mg}$ in 50 MDD patients (Jahangard et al., 2018). Using self- and clinician-reported ratings (BDI and MADRS), omega-3 $1000 \mathrm{mg} /$ day improved symptoms of depression, anxiety, and sleep, as well as emotional 
regulation. Generalisability was limited by the small sample size, inclusion of outpatients, and lack of biomarker analysis. In a systematic review of six studies with elderly depressed patients, Bae et al., 2018 concluded that omega-3 fatty acid supplementation was effective in mild-moderately depressed populations, although at a dose higher than 1g/day (Bae \& Kim, 2018). In addition, omega-3 fatty acids were linked to increased 5-HT and DA production, as well as reduced oxidative stress and inflammatory cytokine levels.

EPO, a growth factor hormone, increases BDNF production, leading to increased neuroplasticity resulting in a neuroprotective effect to facilitate better cognition (Carvalho et al., 2014). In 19 MDD patients, 3 days of EPO 40,000 IU significantly changed facial recognition response, similar to conventional antidepressant effect (Miskowiak et al., 2010). In 40 TRD MDD patients, the same dose of EPO over 8 weeks led to reduced depression severity and improvement in verbal recall and recognition, measured by RAVLT, in comparison to placebo (Miskowiak et al., 2014).

Ott et al., 2016 performed secondary analysis on a 9-week RCT, in which unipolar $(\mathrm{N}=36)$ and bipolar patients $(\mathrm{N}=43)$ received EPO $40,000 \mathrm{IU} / \mathrm{ml}$ or saline infusions (Ott et al., 2016). EPO improved processing speed in attention, memory, and executive function in both groups (Table 5) an effect maintained at 6-week follow up. Objective, not subjective, baseline cognition predicted greater chance of treatment success in EPO patients, particularly in those with greater verbal memory dysfunction, highlighting the importance of these baseline measures. Li et al., 2018 systematically reviewed four RCTs with adjunctive EPO across affective disorders, including those by Miskowiak et al., 2009, and Miskowiak et al., 2014 in MDD, concluding EPO to have potential pro-cognitive effect (Li et al., 2018). Future studies should aim to overcome heterogeneity in cognitive assessment tools, short study durations, exclusion of patients with relevant co-morbidities such as diabetes mellitus, and lack of functional outcome measures and reporting. Currently, Schmidt et al., 2018 are investigating EPO $40,000 I U / \mathrm{ml}$ as an add-on treatment for the cognitive side effects of electroconvulsive therapy (ECT), with the primary outcome a change in composite cognitive score assessing attention, verbal learning, memory, and executive function (Schmidt et al., 2018). Inclusion of structural and fMRI will help explore whether oxidative stress, inflammation, or neuroplasticity biomarkers accompany changes in cognition. 
Metformin, indicated for type 2 diabetes mellitus (T2DM), has been linked to hippocampal neurogenesis and improved cognition. In 58 patients with both MDD and T2DM, metformin $1 \mathrm{~g}-2 \mathrm{~g} /$ day was administered over 24 weeks versus placebo; using the Wechsler Memory Scale, improved cognitive performance was measured across memory, attention, and concentration domains (Guo et al., 2014). To our knowledge, no new trials have yet been published with metformin and cognitive outcomes.

Building on the evidence base for vortioxetine, an RCT conducted by Fourrier et al., 2018 is trialing vortioxetine as an add-on therapy alongside celecoxib 400mg, an antiinflammatory COX-2 inhibitor, or placebo in 200 MDD patients (Fourrier et al., 2018). Interestingly, the trial will stratify patients into 'Depression with inflammation' and 'Depression without inflammation' groups, with CRP levels $>3 \mathrm{mg} / \mathrm{L}$ and $\leq 3 \mathrm{mg} / \mathrm{L}$ respectively, before randomising patients to celecoxib or placebo over 6 weeks. Patients may opt to continue vortioxetine during a 6-month open-label phase. Cognitive measures will encompass global function, emotional processing and social cognition, using the novel cognitive assessment tool, THINC-it. Biological measures will include CRP, TNF- $\alpha$, IL-6 and IL$1 \beta$, generating evidence for biomarker stratification of patients for antidepressant treatment, based on inflammatory status.

Moving forward, this personalised approach will be very important to enable greater rates of treatment success and functional recovery in sub-groups of patients. This is especially important for many of the anti-inflammatory therapies reviewed in this section, for which evidence has been overall positive, but relatively sparse.

\subsubsection{Opport unities for patient st ratification}

While it's true that heterogeneity in cognitive assessments and methodology present several problems, it also offers researchers a unique opportunity to individualise therapeutic approaches and maximise benefit provided by potential pro-cognitive agents. The majority of studies investigating anti-inflammatory treatments have classified patients by depression severity or degree of cognitive impairment, using an assortment of scales and batteries. Very few have incorporated biomarker analysis as outcome measures, imaged microglia, or stratified based on inflammatory markers. 
Given that the correlation between inflammatory markers such as IL-6 and CRP and depression has been well-documented, this is surprising. Chang et al., 2012 explored whether CRP was significantly associated with depressive symptoms and cognitive impairment in 149 medication-free MDD patients, treated with either fluoxetine $20-80 \mathrm{mg}$ or venlafaxine 37.5 $75 \mathrm{mg}$ over 6 weeks (Chang et al., 2012). Depression severity was measured using HAM-D, and fasting plasma CRP levels measured at baseline and 6 weeks. The neurocognitive battery consisted of the CPT, WCST, and Finger-Tapping Test (FTT). Although no significant link was found between CRP levels and HAM-D score at trial completion, poor psychomotor speed and executive function were significantly associated with higher baseline CRP before treatment. 'Certain patients' with high CRP levels may have enhanced antidepressant response and cognitive improvements, and so targeting these may be the key to treatment success.

Galecki et al., 2018 recently reviewed the anti-inflammatory mechanism of SSRIS and SNRIs. Venlafaxine alleviates renovascular hypertension, reducing endothelial dysfunction, oxidative stress, cholinergic dysfunction and inflammation, which contribute to cognitive impairment (Galecki et al., 2018). Small but significant effects have been reported on activated microglia and to inhibit superoxide generation. SSRIs were found to have neuroprotective, anti-inflammatory, anti-oxidant and anti-apoptotic properties. This is especially interesting given the reported pro-cognitive effects of SNRIs, and the inconsistent results on cognition with SSRIs and SNRIs. Patients with greater baseline inflammation may see greater cognitive improvements, although this is difficult to confirm without blood-based biomarker analysis.

Pariante and colleagues, 2017 have established that not all patients are inflamed to the same degree. Greater inflammation and depression has been recorded in patients exposed to greater childhood stress or maternal depression during foetal neurodevelopment, as well as those with genetic variants pre-disposing them to greater immune response. These genetic variants include G-174C, Banl, and COX2 rs 4648308 polymorphisms in the IL-6, cytosolic phospholipase A2 and COX-2 genes respectively (Pariante, 2017). Further molecular analysis has revealed that people with PLA2 and COX2 mutations have reduced endogenous levels of the anti-inflammatory and potential antidepressant mediators, omega-3 fatty acids, docosahexaenoic acids and eicosapentaenoic acids. If genotype can increase depression risk through altered immune response and anti-inflammatory mediators, this will likely determine 
how patients respond to treatments such as omega-3 or COX-2 inhibitors like celecoxib, and which patients might be most suitable for these treatments.

Where stratification is performed without biomarkers, inclusion of depressed patients without inflammation in trials may dilute results and facilitate negative and inconclusive findings. In one example, melatonin-SR $3 \mathrm{mg}$ has been trialed as an add-on therapy with buspirone $15 \mathrm{mg}$ (Targum et al., 2015). CPFQ scores confirmed improved cognition in the augmentation group. Given that Brown et al., 2018 reported that mutations and polymorphisms in genes such as Per3, Cry1, Clock and Npas2 in MDD may relate to greater degrees of circadian dysfunction, which may in turn affect cognition, these patients with circadian rhythm dysregulation may see far superior benefits with melatonin on cognitive function (Brown et al., 2018). In another study by McGlashan et al., 2018, acute administration of citalopram $30 \mathrm{mg}$ correlated with a $47 \%$ increase in melatonin suppression, resulting in increased sensitivity to light (McGlashan et al., 2018). These results further indicate that circadian light response is subject to variability and may predict treatment outcomes in certain subsets of patients.

Brown et al., 2018 also highlighted findings where omega-3 treatment response was predicted through inflammatory stratification (Rapaport et al., 2016). Five cytokine biomarkers, IL-1 receptor antagonist (IL-ra), IL-6, high-sensitivity CRP (hsCRP), leptin and adiponectin, separated patients into 'high' and 'low' grades of inflammation, with 'highly' inflamed patients responding better to eicosapentaenoic acid (EPA) than placebo. Although no overall significant improvements were reported, these findings show that stratification based on inflammatory markers is both feasible and highly relevant to study outcomes.

Anti-inflammatory treatments may have therapeutic benefit in patients with exaggerated reactivity to negative information, somatic symptoms and altered reward processes; surprisingly, the role of inflammatory mechanisms in cognitive control and executive function is not well-evidenced in the literature (Dooley et al., 2018). This may be attributable to lack of sensitivity of neurocognitive batteries to inflammatory changes, although other cognitive domains may be affected more by inflammation, such as learning and memory. Only $33-47 \%$ of depressed patients may have high peripheral inflammation, and these are patients most likely to benefit from anti-inflammatory supplements. 
Herder et al., 2018 estimated longitudinal associations between diabetes and depression symptoms in 271 individuals with type 1 and 2 diabetes, assessing concentrations of serum hsCR, IL-6, IL-1 ra, IL-18, and CC-chemokine ligand 2 (CCL2) obtained from two RCTs investigating diabetes and depression (Herder et al., 2018). In T2DM, lower concentrations of hsCRP, IL-18 and IL-1RA correlated with reduced depression symptomatology, and increased CCL2 at baseline correlated with reduced symptom improvement. Although trials with metformin and pioglitazone have produced equivocal results, augmentation in comorbid populations with increased inflammatory markers may see greater benefits.

In summary, stratifying certain subsets of patients and targeting anti-inflammatory therapies according to biological marker levels may be a more successful application of novel treatments, and more likely to lead to definitive results. In some cases, this is already underway. Omega-3 is currently being trialled as a personalised approach in 90 and 100 MDD patients with high peripheral inflammation, as well as 60 MDD patients with cardiovascular disease (NCT02553915; NCT03143075; NCT03072823). Applying this individualised treatment approach with other therapies should help overcome inconclusive results and identify treatment pathways for the certain patients who will benefit the most.

\section{Discussion}

This review evaluated the impact and treatment of cognitive deficits in MDD patients. Despite a wealth of growing knowledge and emerging therapies, current evidence is as yet still equivocal and inconclusive. We posit that there are several key messages for the field to take forward, relating to targeted cognitive interventions, medicines optimisation, patient stratification, and methodological improvements.

\subsection{Importance of targeted and timely interventions}

Cognitive deficits affect patients in both acute and remitted states, with significant short- and long-term impact on quality of life and functionality (Jaeger et al., 2006; Preiss et al., 2009; Baune et al., 2010; Hasselbalch et al., 2011). Executive function, attention, and memory impairments have been strongly associated with poorer outcomes, with attention 
linked to reduced mental and social capabilities. Cognitive deficits do not always present in the same manner, or to the same degree. Increased depression severity correlates with greater magnitude of impairment, and cognition has been found to be worse in first-episode versus multiple-episode patients. Late-onset patients present with more severe dysfunction, particularly in executive function, processing speed, and verbal memory (Bora et al., 2012; Bora et al., 2013).

Importantly, executive function has emerged as the key cognitive domain for psychosocial outcomes, and is the most significant predictor of social cognition, psychosocial, and workplace function for patients in remission. In currently depressed patients, the forward planning subdomain was most associated with overall psychosocial dysfunction, as well as issues with 'autonomy, subjective cognition, and interpersonal relationships'. Cognitive updating was negatively associated with reduced subjective cognition, psychosocial function, and occupational function. Further research into forward planning would be valuable as an indicator of functionality in acute MDD (Knight et al., 2018; Knight \& Baune, 2018).

Despite shared diagnoses and clinical similarities, depression patients present with markedly heterogeneous impairments. As early as first-episode, patients have been reported as 'cognitively preserved', or 'cognitively impaired'. 'Cognitively preserved' patients may recover more quickly than their counterparts and require alternative treatment strategies (Vicent-Gil et al., 2018). Although dysfunction could be identified in first-episode patients via hippocampal atrophy, grey matter reduction in the amygdala, and white matter abnormalities, little research has been conducted on whether cognitive impairments appear before diagnosis as in schizophrenia (Lee et al., 2012; Ma et al., 2007). As memory dysfunction has been identified in some 'at risk' individuals, this is also important for future research. Cognitive ability has predicted depression symptom severity at baseline and at 12-month follow-up, with verbal learning, prospective memory, and executive function the strongest predictors of psychosocial functional outcomes at 3- and 6-month follow-up (Cambridge et al., 2018).

A diagnosis of depression is insufficient evidence to confirm either the presence or absence of cognitive impairment (Keilp et al., 2018). Cognitive deficits are often the result of complex interactions at individual and clinical levels, which causes varying degrees of presentation in depressed patients. Timely identification is essential to preserve functional 
outcomes (Fig 1). The THINC-it tool is an important step in overcoming previous limitations with exhaustive neurocognitive batteries. The assessment, which can be self-administered by patients or applied by health care professionals, could facilitate detection and relieve longterm complications much earlier (McIntyre et al., 2017a; Cha et al., 2017; Baune et al., 2018).

Given that cognitive impairment can lead to depression relapse, poor prognosis, and reduced employment and workplace productivity, the earlier the detection and prevention of these deficits, the better. Cognitive screening must thus begin at diagnosis. Where cognitive impairments are sooner recognised, they can be sooner treated. As acute and remitted patients display differential executive function, this underscores the importance of early stratification and targeted screening in certain subgroups, such as first-episode patients. An on-going commitment is necessary, and efforts should be made throughout a patient's healthcare journey. This might occur at time-point 3 , where adjunct therapy could be administered alongside antidepressant therapy. Additionally, the recruitment of younger patients ( $<65$ years) into research trials at time-point 4 should be considered.

By applying timely, targeted interventions, we can hopefully facilitate earlier identification and improve patient outcomes in both the short-and long-term.

\subsection{0ptimising therapy in cognitive impairment}

Although the case for their treatment is robust, cognitive impairments have yet to be adequately improved by conventional therapies. Antidepressants have presented with varying

intra- and inter-class-dependent results, and no single treatment has been found to have consistently superior effects on cognition.

Despite this, some antidepressants may still have better effects on cognition than others. SNRIs have been linked to improved recovery of episodic and working memory (Tian et al., 2016). Given that some studies have not correlated executive control improvements with depression severity, this underscores that SNRIs may exert pro-cognitive effects via mechanisms independent of depression symptom improvement, linked to increased DA concentrations in the frontal, limbic and parietal areas (Herrera-Guzman et al., 2009). More recent evidence has reported that venlafaxine alleviates renovascular hypertension, exhibiting anti-inflammatory 
effects linked potentially to cognitive improvement. SSRIs have also been found to have neuroprotective, anti-inflammatory, anti-oxidant and anti-apoptotic capabilities, leading to therapeutic and protective effects (Galecki et al., 2018). This is interesting given reported procognitive effects of SNRIs, and the inconsistent results reported with SSRIs and SNRIs. Patients with greater baseline inflammation may also see greater cognitive improvements with these treatments, although this is difficult to confirm without blood-based biomarker analysis.

Conversely, other antidepressants may have worse effects. TCAs such as dothiepin have been associated with decreased CFF performance, linked to its anticholinergic and antihistaminergic pharmacology (Trick et al., 2004). Adverse side effect profiles may compound existing cognitive difficulties, while sedation could lead to pronounced difficulties with cognitive and psychomotor functions, particularly in elderly populations. For this reason, it may be worth considering switching TCAs for alternative antidepressants in depression patients with significant cognitive impairments.

Vortioxetine is a promising candidate for pro-cognitive therapy. Significant improvements have been reported in processing speed, verbal learning, and recall domains. Additionally, over two-thirds of vortioxetine's effect on cognition is due to direct treatment effect (Katona et al., 2012; Mahableshwarkar et al., 2015; McIntyre et al., 2014; Harrison et al., 2016; Vieta et al., 2018). Ketamine may also improve attention and response control in TRD due to antidepressant effect (Chen et al., 2018).

In terms of novel therapies, several agents have potential. Positive but preliminary findings showed that augmentation with stimulants modafinil, LDX, and nicotine may improve attention, episodic and working memory, and executive function (Kaser et al., 2017; Mclntyre et al., 2017b; Gandelman et al., 2018). While the benefits of exercise remain equivocal due to study designs, it is an effective and tolerable add-on therapy (Buschert et al., 2018). Skills training for MDD, similar to Computerised Interactive Remediation of Cognition - a Training for Schizophrenia (CIRCuiTS), could be constructive; if this was accessible, it could have similar positive effects to the 'online homework' used in CR trials (Reeder et al., 2017). Regarding antiinflammatories, omega-3 supplementation showed improved emotional regulation in mild to moderately depressed patients, and EPO improved processing speed in attention, memory, and executive function (Bae \& Kim, 2018; Ott et al., 2016). 
Although some therapies have potential pro-cognitive effects, firm conclusions cannot be made until consistent methodologies are employed. We stress that the field urgently requires more large-scale, randomised, placebo-controlled trials, testing cognition as a primary outcome with adequate, ideally standardised, neurocognitive batteries. Until study designs are improved, we are left with a constellation of potential ideas that cannot be fulfilled using current methods. Together with the number of exciting current studies cited earlier in our review, these changes will be of great future importance, and should shed further light on the emerging role of novel agents in cognitive deficit therapy.

\subsection{An individualised a pproach to cognitive impa irment}

No single population of depression patients is homogenous, and trial participants vary diversely in degrees of depression severity and cognitive impairment. While heterogeneity in cognitive assessments and methodology present us with several problems, these differences offer a unique opportunity to individualise therapies and maximise benefit from pro-cognitive agents. Like cogs that represent distinct functions in machinery, cognition and its domains are highly complex and individual. No one formula can possibly fit all, and therapy may likewise need to reflect this. Certain patient groups are likely to see greater benefit from some therapies more than others, and at different stages of their treatment. By approaching therapy using individual profiles, we may bettertarget impairments using stratified interventions.

This approach is especially important in relation to anti-inflammatory treatments. Since only $33-47 \%$ of depressed patients may have high peripheral inflammation, it follows that it is these patients who are most likely to benefit from anti-inflammatory therapies (Dooley et al., 2018). Additionally, if genotype can increase depression risk through altered immune response and increased levels of inflammatory mediators, this could further determine how patients respond to treatments such as omega-3 supplementation, or COX-2 inhibitors such as celecoxib, for which inflamed individuals might be more suitable than others (Fourrier et al., 2018). Stratifying subsets of patients and targeting agents according to biological marker concentrations may be a more successful application of novel treatments and will be more likely to lead to more definitive results. 
Cognition in MDD is underpinned by a variety of pathophysiological processes. This complex, multi-faceted picture may be best tackled as a therapeutic profile, where different areas can be modulated (fig 2). At one level, we can review antidepressants and consider augmentation with novel agents. On another, we must individualise therapeutic approaches. We should commit to on-going screening using tools such as THINC-it, and test more rigorously for impairments at trial inclusion. Patient stratification should be improved, i.e. by using 'cognitively preserved' and 'cognitively impaired', or 'depression with inflammation' and 'depression without inflammation', and biomarkers incorporated into study designs (Fourrier et al., 2018; Vicent-Gil et al., 2018). Evidence has underscored that executive function, attention, and memory impairments are most significantly associated with poorer outcomes in MDD patients. These specific domains should therefore be targeted, and further novel therapies and target-engagement mechanisms explored. This framework is supported by positive but preliminary findings, as current evidence is not robust enough to support immediate implementation into practice. Further replication and validation studies are required.

\subsection{Methodological limitations and future recommendations}

Despite significant regulatory and research advances in recent years, the 'patchwork set of methods' used in studies have all greatly hampered progress (Keefe et al., 2016).

Due to inadequately powered trials and heterogeneous assessments, current results are promising, but remain equivocal. Few studies have measured objective or subjective cognitive deficits at baseline, or tested cognition as a primary outcome. Numerous studies have been inadequate in their detail of medication, including names and doses, and have not always included treatment effect adjustments. Lack of follow-up studies have made valuable longitudinal analysis difficult, particularly with small samples of patients ranging from mild to severely depressed. Most anti-inflammatory studies have classified patients by severity of depression or cognitive impairment, using an assortment of scales and batteries. Very few have incorporated biomarker analysis, imaged microglia, or stratified patients based on inflammatory marker measures.

The assortment of cognitive assessments used has made true comparison difficult. With so many different cognitive tests, the likelihood of methodological inconsistences is high. 
These results not only provide research setbacks, but also confirm the need for standardised neurocognitive measures in MDD, which should be sensitive and accurate enough to detect varying and highly individual degrees of cognitive impairment in depressed patients. A standardised test battery is critical in order to improve future studies, as has already been achieved by MATRICS in schizophrenia.

To overcome limitations and commit to making true advances for patients, we outline five research recommendations (fig 3). First, a standardised cognitive battery should be developed. Second, trial design should include patients below $<65$ years, with adequate control groups and larger sample sizes. More longitudinal designs, large-scale effectiveness trials and follow-ups would also enable better insight into long-term cognitive effects. Third, sex differences should be researched in greater detail. Despite increased susceptibility to both depression and cognitive impairment, treatment in women with MDD has thus far received inadequate attention. Even though females generally outnumber males in trials, few studies investigated whether differences in cognition may exist, the impact of hormonal status and possible treatment implications. Fourth, patient stratification should take into consideration diverse pathophysiology and aetiology patterns, e.g. immune dysfunction, and target novel therapies accordingly. This should improve target-engagement and delivery to appropriate populations. The addition of more biomarkers and fMRI in study designs would also be ideal. Fifth, we should continue research efforts to validate further novel therapies.

It is important to note that there are limitations of our current review. In order to give a focused assessment of MDD, studies with participants with other diagnoses of depression (bipolar, schizoaffective disorder, etc) were excluded. Use of the PubMed and ScienceDirect search engines may have limited findings to studies only in the public domain, without access to pre-clinical trial data, and may have neglected to identify some studies. Variations in clinical trial designs have also confounded results and made comparisons between studies difficult without standardised practice.

\section{Conclusion}


Cognitive deficits in MDD are an exciting and important area of research, with valuable recent progress. To ensure future development, four key recommendations are suggested. One, to use THINC-it for earlier detection of cognitive deficits. Two, to develop one unified and standardised cognitive testing battery. Three, to improve clinical trial designs to include more gender analysis, younger patients, longitudinal designs, and patient stratification methods. Four, to continue research efforts to validate therapeutic regimens for cognitive impairment, working towards a 'cognitive profile'. This would enable combinations of antidepressant monotherapy and novel adjuvants to selectively treat different cognitive domains. These developments combined should significantly improve the negative impact of cognitive deficits in patients and overcome the methodological difficulties with on-going research efforts in the field.

\section{Conflict of Interest statement}

The authors declare that there are no conflicts of interest.

\section{References}

Antypa, N., Smelt, A. H., Strengholt, A., \& Van der Does, A. J. (2012). Effects of omega-3 fatty acid supplementation on mood and emotional information processing in recovered depressed individuals. J Psychopharmacol, 26, 738-743.

Bae, J. H., \& Kim, G. (2018). Systematic review and meta-analysis of omega-3-fatty acids in elderly patients with depression. Nutr Res, 50, 1-9.

Ballard, E. D., Yarrington, J. S., Farmer, C. A., Lener, M. S., Kadriu, B., Lally, N., Williams, D., Machado-Vieira, R., Niciu, M. J., Park, L., \& Zarate, C. A., Jr. (2018). Parsing the heterogeneity of depression: An exploratory factor analysis across commonly used depression rating scales. J Affect Disord, 231, 51-57.

Baune, B. T., Malhi, G. S., Morris, G., Outhred, T., Hamilton, A., Das, P., Bass ett, D., Berk, M., Boyce, P., Lyndon, B., Mulder, R., Parker, G., \& Singh, A. B. (2018). Cognition in depression: Can we THINC-it better? J Affect Disord, 225, 559-562. 
Baune, B. T., Miller, R., McAfoose, J., Johnson, M., Quirk, F., \& Mitchell, D. (2010). The role of cognitive impairment in general functioning in major depression. Psychiatry Res, 176, 183-189.

Belgaied, W., Samp, J., Vimont, A., Remuzat, C., Aballea, S., El Hammi, E., Kooli, A., Toumi, M., \& Akhras, K. (2014). Routine clinical assessment of cognitive functioning in schizophrenia, major depressive disorder, and bipolar disorder. Eur Neuropsychopharmacol, 24, 133-141.

Bergfeld, I. O., Mantione, M., Hoogendoorn, M. L. C., Ruhe, H. G., Horst, F., Notten, P., van Laarhoven, J., van den Munckhof, P., Beute, G., Schuurman, P. R., \& Denys, D. (2017). Impact of deep brain stimulation of the ventral anterior limb of the internal capsule on cognition in depression. Psychol Med, 47, 1647-1658.

Bora, E., Fornito, A., Pantelis, C., \& Yucel, M. (2012). Gray matter abnormalities in Major Depressive Disorder: a meta-analysis of voxel based morphometry studies. J Affect Disord, 138, 9-18.

Bora, E., Harrison, B. J., Yucel, M., \& Pantelis, C. (2013). Cognitive impairment in euthymic major depressive disorder: a meta-analysis. Psychol Med, 43, 2017-2026.

Bortolato, B., Carvalho, A. F., \& McIntyre, R. S. (2014). Cognitive dysfunction in major depressive disorder: a state-of-the-art clinical review. CNS Neurol Disord Drug Targets, 13, 1804-1818.

Bowie, C. R., Gupta, M., Holshausen, K., Jokic, R., Best, M., \& Milev, R. (2013). Cognitive remediation for treatment-resistant depression: effects on cognition and functioning and the role of online homework. J Nerv Ment Dis, 201, 680-685.

Brondino, N., Rocchetti, M., Fusar-Poli, L., Codrons, E., Correale, L., Vandoni, M., Barbui, C., \& Politi, P. (2017). A systematic review of cognitive effects of exercise in depression. Acta Psychiatr Scand, 135, 285-295.

Brown, G. M., Mclntyre, R. S., Rosenblat, J., \& Hardeland, R. (2018). Depressive disorders: Processes leading to neurogeneration and potential novel treatments. Prog Neuropsychopharmacol Biol Psychiatry, 80, 189-204.

Buckman, J. E. J., Underwood, A., Clarke, K., Saunders, R., Hollon, S. D., Fearon, P., \& Pilling, S. (2018). Risk factors for relapse and recurrence of depression in adults and how 
they operate: A four-phase systematic review and meta-synthesis. Clin Psychol Rev, 64, 13-38.

Buschert, V., Prochazka, D., Bartl, H., Diemer, J., Malchow, B., Zwanzger, P., \& Brunnauer, A. (2018). Effects of physical activity on cognitive performance: a controlled clinical study in depressive patients. Eur Arch Psychiatry Clin Neurosci.

Cambridge, O. R., Knight, M. J., Mills, N., \& Baune, B. T. (2018). The clinical relationship between cognitive impairment and psychosocial functioning in major depressive disorder: A systematic review. Psychiatry Res, 269, 157-171.

Carvalho, A. F., Miskowiak, K. K., Hyphantis, T. N., Kohler, C. A., Alves, G. S., Bortolato, B., PM, G. S., Machado-Vieira, R., Berk, M., \& McIntyre, R. S. (2014). Cognitive dysfunction in depression - pathophysiology and novel targets. CNS Neurol Disord Drug Targets, 13, 1819-1835.

Cha, D. S., Carmona, N. E., Subramaniapillai, M., Mansur, R. B., Lee, Y., Hon Lee, J., Lee, J., Rosenblat, J. D., Shekotikhina, M., Park, C., Rong, C., Greer, T. L., Lam, R., Baune, B. T., Harrison, J., \& McIntyre, R. S. (2017). Cognitive impairment as measured by the THINC-integrated tool (THINC-it): Association with psychosocial function in major depressive disorder. J Affect Disord, 222, 14-20.

Chang, H. H., Lee, I. H., Gean, P. W., Lee, S. Y., Chi, M. H., Yang, Y. K., Lu, R. B., \& Chen, P. S. (2012). Treatment response and cognitive impairment in major depression: association with C-reactive protein. Brain Behav Immun, 26, 90-95.

Chen, M. H., Li, C. T., Lin, W. C., Hong, C. J., Tu, P. C., Bai, Y. M., Cheng, C. M., \& Su, T. P. (2018). Cognitive function of patients with treatment-resistant depression after a single low dose of ketamine infusion. J Affect Disord, 241, 1-7.

Clark, M., DiBenedetti, D., \& Perez, V. (2016). Cognitive dysfunction and work productivity in major depressive disorder. Expert Rev Pharmacoecon Outcomes Res, 16, 455-463.

Cogstate. Cognigram Detects Cognitive Impairment In Schizophrenia Patients. [ONLINE]. Available from: https://www.cogstate.com/cognigram-detects-cognitive-impairmentschizophrenia-patients [Accessed 8 December 2018]. 
Culang, M. E., Sneed, J. R., Keilp, J. G., Rutherford, B. R., Pelton, G. H., Devanand, D. P., \& Roose, S.P. (2009). Change in cognitive functioning following acute antidepressant treatment in late-life depression. Am J Geriatr Psychiatry, 17, 881-888.

Culang-Reinlieb, M. E., Sneed, J. R., Keilp, J. G., \& Roose, S. P. (2012). Change in cognitive functioning in depressed older adults following treatment with sertraline or nortriptyline. Int J Geriatr Psychiatry, 27, 777-784.

De Berardis, D., Orsolini, L., Serroni, N., Girinelli, G., lasevoli, F., Tomasetti, C., de Bartolomeis, A., Mazza, M., Valchera, A., Fornaro, M., Perna, G., Piersanti, M., Di Nicola, M., Cavuto, M., Martinotti, G., \& Di Giannantonio, M. (2016). A comprehensive review on the efficacy of S-Adenosyl-L-methionine in Major Depressive Disorder. CNS Neurol Disord Drug Targets, 15, 35-44.

DeBattista, C., Lembke, A., Solvason, H. B., Ghebremichael, R., \& Poirier, J. (2004). A prospective trial of modafinil as an adjunctive treatment of major depression. J Clin Psychopharmacol, 24, 87-90.

Dooley, L. N., Kuhlman, K. R., Robles, T. F., Eisenberger, N. I., Craske, M. G., \& Bower,J. E. (2018). The role of inflammation in core features of depression: Insights from paradigms using exogenously-induced inflammation. Neurosci Biobehav Rev, 94, 219-237.

Doraiswamy, P. M., Krishnan, K. R., Oxman, T., Jenkyn, L. R., Coffey, D. J., Burt, T., \& Clary, C. M. (2003). Does antidepressant therapy improve cognition in elderly depressed patients? J Gerontol A Biol Sci Med Sci, 58, M1137-1144.

Dosenbach, N. U., Fair, D. A., Miezin, F. M., Cohen, A. L., Wenger, K. K., Dosenbach, R. A., Fox, M. D., Snyder, A. Z., Vincent, J. L., Raichle, M. E., Schlaggar, B. L., \& Petersen, S. E. (2007). Distinct brain networks for adaptive and stable task control in humans. Proc Natl Acad Sci U S A, 104, 11073-11078.

Fourrier, C., Sampson, E., Mills, N. T., \& Baune, B. T. (2018). Anti-inflammatory treatment of depression: study protocolfor a randomised controlled trial of vortioxetine augmented with celecoxib or placebo. Trials, 19, 447. 
Gadad, B. S., Jha, M. K., Czysz, A., Furman, J. L., Mayes, T. L., Emslie, M. P., \& Trivedi, M. H. (2018). Peripheral biomarkers of major depression and antidepressant treatment response: Current knowledge and future outlooks. J Affect Disord, 233, 3-14.

Galecki, P., Mossakowska-Wojcik, J., \& Talarowska, M. (2018). The anti-inflammatory mechanism of antidepressants - SSRIs, SNRIs. Prog Neuropsychopharmacol Biol Psychiatry, 80, 291-294.

Gandelman, J. A., Newhouse, P., \& Taylor, W. D. (2018). Nicotine and networks: Potential for enhancement of mood and cognition in late-life depression. Neurosci Biobehav Rev, 84, 289-298.

Giacobbe, P., Rakita, U., Lam, R., Milev, R., Kennedy, S. H., \& McIntyre, R. S. (2018). Efficacy and tolerability of lisdexamfetamine as an antidepressant augmentation strategy: A meta-analysis of randomized controlled trials. J Affect Disord, 226, 294-300.

Gorlyn, M., Keilp, J., Burke, A., Oquendo, M., Mann, J. J., \& Grunebaum, M. (2015). Treatment-related improvement in neuropsychological functioning in suicidal depressed patients: paroxetine vs. bupropion. Psychiatry Res, 225, 407-412.

Greer, T. L., Furman, J. L., \& Trivedi, M. H. (2017). Evaluation of the benefits of exercise on cognition in major depressive disorder. Gen Hosp Psychiatry, 49, 19-25.

Greer, T. L., Grannemann, B. D., Chansard, M., Karim, A. I., \& Trivedi, M. H. (2015). Dosedependent changes in cognitive function with exercise augmentation for major depression: results from the TREAD study. Eur Neuropsychopharmacol, 25, 248-256.

Guo, M., Mi, J., Jiang, Q. M., Xu, J. M., Tang, Y. Y., Tian, G., \& Wang, B. (2014). Metformin may produce antidepressant effects through improvement of cognitive function among depressed patients with diabetes mellitus. Clin Exp Pharmacol Physiol, 41, $650-656$

Harrison, J. E., Lophaven, S., \& Olsen, C. K. (2016). Which Cognitive Domains are Improved by Treatment with Vortioxetine? Int J Neuropsychopharmacol.

Hasselbalch, B. J., Knorr, U., \& Kessing, L. V. (2011). Cognitive impairment in the remitted state of unipolar depressive disorder: a systematic review. J Affect Disord, 134, 2031. 
Herder, C., Schmitt, A., Budden, F., Reimer, A., Kulzer, B., Roden, M., Haak, T., \& Hermanns, N. (2018). Longitudinal associations between biomarkers of inflammation and changes in depressive symptoms in patients with type 1 and type 2 diabetes. Psychone uroendocrinology, 91, 216-225.

Herrera-Guzman, I., Gudayol-Ferre, E., Herrera-Abarca, J. E., Herrera-Guzman, D., Montelongo-Pedraza, P., Padros Blazquez, F., Pero-Cebollero, M., \& Guardia-Olmos, J. (2010). Major Depressive Disorder in recovery and neuropsychological functioning: effects of selective serotonin reuptake inhibitor and dual inhibitor depression treatments on residual cognitive deficits in patients with Major Depressive Disorder in recovery. J Affect Disord, 123, 341-350.

Herrera-Guzman, I., Gudayol-Ferre, E., Herrera-Guzman, D., Guardia-Olmos, J., HinojosaCalvo, E., \& Herrera-Abarca, J. E. (2009). Effects of selective serotonin reuptake and dual serotonergic-noradrenergic reuptake treatments on memory and mental processing speed in patients with major depressive disorder. J Psychiatr Res, 43, 855-863.

Jaeger, J., Berns, S., Uzelac, S., \& Davis-Conway, S. (2006). Neurocognitive deficits and disability in major depressive disorder. Psychiatry Res, 145, 39-48.

Jahangard, L., Sadeghi, A., Ahmadpanah, M., Holsboer-Trachsler, E., Sadeghi Bahmani, D., Haghighi, M., \& Brand, S. (2018). Influence of adjuvant omega-3-polyunsaturated fatty acids on depression, sleep, and emotion regulation among outpatients with major depressive disorders - Results from a double-blind, randomized and placebocontrolled clinical trial. J Psychiatr Res, 107, 48-56.

Kaser, M., Deakin, J. B., Michael, A., Zapata, C., Bansal, R., Ryan, D., Cormack, F., Rowe,J. B., \& Sahakian, B. J. (2017). Modafinil Improves Episodic Memory and Working Memory Cognition in Patients With Remitted Depression: A Double-Blind, Randomized, Placebo-Controlled Study. Biol Psychiatry Cogn Neurosci Neuroimaging, 2, 115-122.

Katona, C., Hansen, T., \& Olsen, C. K. (2012). A randomized, double-blind, placebocontrolled, duloxetine-referenced, fixed-dose study comparing the efficacy and safety of Lu AA21004 in elderly patients with major depressive disorder. Int Clin Psychopharmacol, 27, 215-223. 
Keefe, R.S. (2014) The longitudinal course of cognitive impairment in schizophrenia: an examination of data from premorbid through post-treatment phases of illness. J Clin Psychiatry, 75 (suppl 2), 8-1.

Keefe, R. S. (2016). Treating cognitive impairment in depression: an unmet need. Lancet Psychiatry, 3, 392-393.

Keefe, R. S., McClintock, S. M., Roth, R. M., Doraiswamy, P. M., Tiger, S., \& Madhoo, M. (2014). Cognitive effects of pharmacotherapy for major depressive disorder: a systematic review. J Clin Psychiatry, 75, 864-876.

Keilp, J. G., Madden, S. P., Gorlyn, M., Burke, A. K., Oquendo, M. A., \& Mann, J. J. (2018). The lack of meaningful association between depression severity measures and neurocognitive performance. J Affect Disord, 241, 164-172.

Knight, M. J., Air, T., \& Baune, B. T. (2018). The role of cognitive impairment in psychosocial functioning in remitted depression. J Affect Disord, 235, 129-134.

Knight, M. J., \& Baune, B. T. (2018). Executive Subdomains Are Differentially Associated With Psychosocial Outcomes in Major Depressive Disorder. Front Psychiatry, 9, 309.

Kubu, C. S., Brelje, T., Butters, M. A., Deckersbach, T., Malloy, P., Moberg, P., Troster, A. I., Williamson, E., Baltuch, G. H., Bhati, M. T., Carpenter, L. L., Dougherty, D. D., Howland, R. H., Rezai, A. R., \& Malone, D. A., Jr. (2017). Cognitive outcome after ventral capsule/ventral striatum stimulation for treatment-resistant major depression. J Neurol Neurosurg Psychiatry, 88, 262-265.

Lavretsky, H., Reinlieb, M., St Cyr, N., Siddarth, P., Ercoli, L. M., \& Senturk, D. (2015). Citalopram, methylphenidate, or their combination in geriatric depression: a randomized, double-blind, placebo-controlled trial. Am J Psychiatry, 172, 561-569. Lee, R. S., Hermens, D. F., Porter, M. A., \& Redoblado-Hodge, M. A. (2012). A meta-analysis of cognitive deficits in first-episode Major Depressive Disorder. J Affect Disord, 140, 113-124.

Levkovitz, Y., Alpert, J. E., Brintz, C. E., Mischoulon, D., \& Papakostas, G. I. (2012). Effects of S-adenosylmethionine augmentation of serotonin-reuptake inhibitor antidepressants on cognitive symptoms of major depressive disorder. J Affect Disord, 136, 11741178. 
Levkovitz, Y., Harel, E. V., Roth, Y., Braw, Y., Most, D., Katz, L. N., Sheer, A., Gersner, R., \& Zangen, A. (2009). Deep transcranial magnetic stimulation over the prefrontal cortex: evaluation of antidepressant and cognitive effects in depressive patients. Brain Stimul, 2, 188-200.

Li, X. B., Zheng, W., Ning, Y. P., Cai, D. B., Yang, X. H., Ungvari, G. S., Ng, C. H., Wang, C. Y., \& Xiang, Y. T. (2018b). Erythropoietin for Cognitive Deficits Associated with Schizophrenia, Bipolar Disorder, and Major Depression: A Systematic Review. Pharmacopsychiatry, 51, 100-104.

Listunova, L., Roth, C., Bartolovic, M., Kienzle, J., Bach, C., Weisbrod, M., \& Roesch-Ely, D. (2018). Cognitive Impairment Along the Course of Depression: Non-Pharmacological Treatment Options. Psychopathology, 51, 295-305.

Ma, N., Li, L., Shu, N., Liu, J., Gong, G., He, Z., Li, Z., Tan, L., Stone, W. S., Zhang, Z., Xu, L., \& Jiang, T. (2007). White matter abnormalities in first-episode, treatment-naive young adults with major depressive disorder. Am J Psychiatry, 164, 823-826.

Madhoo, M., Keefe, R. S., Roth, R. M., Sambunaris, A., Wu, J., Trivedi, M. H., Anderson, C. S., \& Lasser, R. (2014). Lisdexamfetamine dimesylate augmentation in adults with persistent executive dysfunction after partial or full remission of major depressive disorder. Neuropsychopharmacology, 39, 1388-1398.

Mahableshwarkar, A. R., Zajecka, J., Jacobson, W., Chen, Y., \& Keefe, R. S. (2015). A Randomized, Placebo-Controlled, Active-Reference, Double-Blind, Flexible-Dose Study of the Efficacy of Vortioxetine on Cognitive Function in Major Depressive Disorder. Neuropsychopharmacology, 40, 2025-2037.

Marder, S. R., \& Fenton, W. (2004). Measurement and Treatment Research to Improve Cognition in Schizophrenia: NIMH MATRICS initiative to support the development of agents for improving cognition in schizophrenia. Schizophr Res, 72, 5-9.

Mattingly, G., Anderson, R. H., Mattingly, S. G., \& Anderson, E. Q. (2016). The impact of cognitive challenges in major depression: the role of the primary care physician. Postgrad Med, 128, 665-671. 
McGlashan, E. M., Nandam, L. S., Vidafar, P., Mansfield, D. R., Rajaratnam, S. M. W., \& Cain, S. W. (2018). The SSRI citalopram increases the sensitivity of the human circadian system to light in an acute dose. Psychopharmacology (Berl), 235, 3201-3209.

McIntyre, R. S., Best, M. W., Bowie, C. R., Carmona, N. E., Cha, D. S., Lee, Y., Subramaniapillai, M., Mansur, R. B., Barry, H., Baune, B. T., Culpepper, L., Fossati, P., Greer, T. L., Harmer, C., Klag, E., Lam, R. W., Wittchen, H. U., \& Harrison, J. (2017a). The THINC-Integrated Tool (THINC-it) Screening Assessment for Cognitive Dysfunction: Validation in Patients With Major Depressive Disorder. J Clin Psychiatry, $78,873-881$.

McIntyre, R. S., Lee, Y., Zhou, A. J., Rosenblat, J. D., Peters, E. M., Lam, R. W., Kennedy, S. H., Rong, C., \& Jerrell, J. M. (2017b). The Efficacy of Psychostimulants in Major Depressive Episodes: A Systematic Review and Meta-Analysis. J Clin Psychopharmacol, 37, 412-418.

McIntyre, R. S., Lophaven, S., \& Olsen, C. K. (2014). A randomized, double-blind, placebocontrolled study of vortioxetine on cognitive function in depressed adults. Int $J$ Neuropsychopharmacol, 17, 1557-1567.

Miskowiak, K. W., Favaron, E., Hafizi, S., Inkster, B., Goodwin, G. M., Cowen, P. J., \& Harmer, C. J. (2010). Erythropoietin modulates neural and cognitive processing of emotional information in biomarker models of antidepressant drug action in depressed patients. Psychopharmacology (Berl), 210, 419-428.

Miskowiak, K. W., Ott, C. V., Petersen, J. Z., \& Kessing, L. V. (2016). Systematic review of randomized controlled trials of candidate treatments for cognitive impairment in depression and methodological challenges in the field. Eur Neuropsychopharmacol, 26, 1845-1867.

Miskowiak, K. W., Vinberg, M., Christensen, E. M., Bukh, J. D., Harmer, C. J., Ehrenreich, H., \& Kessing, L. V. (2014). Recombinant human erythropoietin for treating treatmentresistant depression: a double-blind, randomized, placebo-controlled phase 2 trial. Neuropsychopharmacology, 39, 1399-1408. 
Motter, J. N., Pimontel, M. A., Rindskopf, D., Devanand, D. P., Doraiswamy, P. M., \& Sneed, J. R. (2016). Computerized cognitive training and functional recovery in major depressive disorder: A meta-analysis. J Affect Disord, 189, 184-191.

Murrough, J. W., Burdick, K. E., Levitch, C. F., Perez, A. M., Brallie r, J. W., Chang, L. C., Foulkes, A., Charney, D. S., Mathew, S.J., \& losifescu, D. V. (2015). Neurocognitive effects of ketamine and association with antidepressant response in individuals with treatment-resistant depression: a randomized controlled trial. Neuropsychopharmacology, 40, 1084-1090.

Noda, Y., Zomorrodi, R., Daskalakis, Z. J., Blumberger, D. M., \& Nakamura, M. (2018). Enhanced theta-gamma coupling associated with hippocampal volume increase following high-frequency left prefrontal repetitive transcranial magnetic stimulation in patients with major depression. Int J Psychophysiol, 133, 169-174.

Ott, C. V., Vinberg, M., Kessing, L. V., \& Miskowiak, K. W. (2016). The effect of erythropoietin on cognition in affective disorders - Associations with baseline deficits and change in subjective cognitive complaints. Eur Neuropsychopharmacol, 26, 1264-1273.

Papakostas, G. I., Petersen, T., Mahal, Y., Mischoulon, D., Nierenberg, A. A., \& Fava, M. (2004). Quality of life assessments in major depressive disorder: a review of the literature. General Hospital Psychiatry, 26, 13-17.

Pariante, C. M. (2017). Why are depressed patients inflamed? A reflection on 20 years of research on depression, glucocorticoid resistance and inflammation. Eur Neuropsychopharmacol, 27, 554-559.

Preiss, M., Kucerova, H., Lukavsky, J., Stepankova, H., Sos, P., \& Kawaciukova, R. (2009). Cognitive deficits in the euthymic phase of unipolar depression. Psychiatry Res, 169, 235-239.

Rapaport, M. H., Nierenberg, A. A., Schettler, P. J., Kinkead, B., Cardoos, A., Walker, R., \& Mischoulon, D. (2016). Inflammation as a predictive biomarker for response to omega-3 fatty acids in major depressive disorder: a proof-of-concept study. Mol Psychiatry, 21, 71-79. 
Raskin, J., Wiltse, C. G., Siegal, A., Sheikh, J., Xu, J., Dinkel, J. J., Rotz, B. T., \& Mohs, R. C. (2007). Efficacy of duloxetine on cognition, depression, and pain in elderly patients with major depressive disorder: an 8-week, double-blind, placebo-controlled trial. Am J Psychiatry, 164, 900-909.

Reddy, S., Fayyad, R., Edgar, C. J., Guico-Pabia, C. J., \& Wesnes, K. (2016). The effect of desvenlafaxine on cognitive functioning in employed outpatients with major depressive disorder: a substudy of a randomized, double-blind, placebo-controlled trial. J Psychopharmacol, 30, 559-567.

Reeder, C., Huddy, V., Cella, M., Taylor, R., Greenwood, K., Landau, S., \& Wykes, T. (2017). A new generation computerised metacognitive cognitive remediation programme for schizophrenia (CIRCuiTS): a randomised controlled trial. Psychol Med, 1-11.

Regier, D. A., Kuhl, E. A., \& Kupfer, D. J. (2013). The DSM-5: Classification and criteria changes. World Psychiatry, 12, 92-98.

Richards, C., losifescu, D. V., Mago, R., Sarkis, E., Reynolds, J., Geibel, B., \& Dauphin, M. (2017). A randomized, double-blind, placebo-controlled, dose-ranging study of lisdexamfetamine dimesylate augmentation for major depressive disorder in adults with inadequate response to antidepressant therapy. J Psychopharmacol, 31, 11901203.

Rock, P. L., Roiser, J. P., Riedel, W. J., \& Blackwell, A. D. (2014). Cognitive impairment in depression: a systematic review and meta-analysis. Psychol Med, 44, 2029-2040.

Rogers, P. J., Appleton, K. M., Kessler, D., Peters, T. J., Gunnell, D., Hayward, R. C., Heatherley, S. V., Christian, L. M., McNaughton, S. A., \& Ness, A. R. (2008). No effect of n-3 long-chain polyunsaturated fatty acid (EPA and DHA) supplementation on depressed mood and cognitive function: a randomised controlled trial. Br J Nutr, 99, $421-431$.

Roiser, J. P., \& Sahakian, B.J. (2013). Hot and cold cognition in depression. CNS Spectr, 18, 139-149.

Rosenblat, J. D., Kakar, R., \& McIntyre, R. S. (2015). The Cognitive Effects of Antidepressants in Major Depressive Disorder: A Systematic Review and Meta-Analysis of Randomized Clinical Trials. Int J Neuropsychopharmacol, 19. 
Salagre, E., Grande, I., Sole, B., Sanchez-Moreno, J., \& Vieta, E. (2018). Vortioxetine: A new alternative for the treatment of major depressive disorder. Rev Psiquiatr Salud Ment, $11,48-59$.

Salagre, E., Sole, B., Tomioka, Y., Fernandes, B. S., Hidalgo-Mazzei, D., Garriga, M., Jimenez, E., Sanchez-Moreno, J., Vieta, E., \& Grande, I. (2017). Treatment of neurocognitive symptoms in unipolar depression: A systematic review and future perspectives. J Affect Disord, 221, 205-221.

Salehinejad, M. A., Ghanavai, E., Rostami, R., \& Nejati, V. (2017). Cognitive control dysfunction in emotion dysregulation and psychopathology of major depression (MD): Evidence from transcranial brain stimulation of the dorsolateral prefrontal cortex (DLPFC). J Affect Disord, 210, 241-248.

Sanchez, C., Asin, K. E., \& Artigas, F. (2015). Vortioxetine, a novel antidepressant with multimodal activity: review of preclinical and clinical data. Pharmacol Ther, 145, 4357.

Sarris, J., Byrne, G. J., Bousman, C., Stough, C., Murphy, J., MacDonald, P., Adams, L., Nazareth, S., Oliver, G., Cribb, L., Savage, K., Menon, R., Chamoli, S., Berk, M., Ng, C., \& Mischoulon, D. (2018). Adjunctive S-adenosylmethionine (SAMe) in treating nonremittent major depressive disorder: An 8-week double-blind, randomized, controlled trial(). Eur Neuropsychopharmacol, 28, 1126-1136.

Schmidt, L. S., Petersen,J. Z., Vinberg, M., Hageman, I., Olsen, N. V., Kessing, L. V., Jorgensen, M. B., \& Miskowiak, K. W. (2018). Erythropoietin as an add-on treatment for cognitive side effects of electroconvulsive therapy: a study protocol for a randomized controlled trial. Trials, 19, 234.

Seeberg, I., Kjaerstad, H. L., \& Miskowiak, K. W. (2018). Neural and Behavioral Predictors of Treatment Efficacy on Mood Symptoms and Cognition in Mood Disorders: A Systematic Review. Front Psychiatry, 9, 337.

Shilyansky, C., Williams, L. M., Gyurak, A., Harris, A., Usherwood, T., \& Etkin, A. (2016). Effect of antidepressant treatment on cognitive impairments associated with depression: a randomised longitudinal study. Lancet Psychiatry, 3, 425-435. 
Shiroma, P. R., Albott, C. S., Johns, B., Thuras, P., Wels, J., \& Lim, K. O. (2014). Neurocognitive performance and serial intravenous subanesthetic ketamine in treatment-resistant depression. Int J Neuropsychopharmacol, 17, 1805-1813.

Smith, J., Browning, M., Conen, S., Smallman, R., Buchbjerg, J., Larsen, K. G., Olsen, C. K., Christensen, S. R., Dawson, G. R., Deakin, J. F., Hawkins, P., Morris, R., Goodwin, G., \& Harmer, C. J. (2018). Vortioxetine reduces BOLD signal during performance of the $\mathrm{N}$-back working memory task: a randomised neuroimaging trial in remitted depressed patients and healthy controls. Mol Psychiatry, 23, 1127-1133.

Soczynska, J. K., Ravindran, L. N., Styra, R., McIntyre, R. S., Cyriac, A., Manierka, M. S., \& Kennedy, S. H. (2014). The effect of bupropion XL and escitalopram on memory and functional outcomes in adults with major depressive disorder: results from a randomized controlled trial. Psychiatry Res, 220, 245-250.

Sole, B., Jimenez, E., Martinez-Aran, A., \& Vieta, E. (2015). Cognition as a target in major depression: new developments. Eur Neuropsychopharmacol, 25, 231-247.

Targum, S. D., Wedel, P. C., \& Fava, M. (2015). Changes in cognitive symptoms after a buspirone-melatonin combination treatment for Major Depressive Disorder. J Psychiatr Res, 68, 392-396.

Tian, Y., Du, J., Spagna, A., Mackie, M. A., Gu, X., Dong, Y., Fan, J., \& Wang, K. (2016). Venlafaxine treatment reduces the deficit of executive control of attention in patients with major depressive disorder. Sci Rep, 6, 28028.

Trapp, W., Engel, S., Hajak, G., Lautenbacher, S., \& Gallhofer, B. (2016). Cognitive remediation for depressed inpatients: Results of a pilot randomized controlled trial. Aust N Z J Psychiatry, 50, 46-55.

Trick, L., Stanley, N., Rigney, U., \& Hindmarch, I. (2004). A double-blind, randomized, 26week study comparing the cognitive and psychomotor effects and efficacy of $75 \mathrm{mg}$ (37.5 mg b.i.d.) venlafaxine and $75 \mathrm{mg}$ ( $25 \mathrm{mg}$ mane, $50 \mathrm{mg}$ nocte) dothiepin in elderly patients with moderate major depression being treated in general practice. $J$ Psychopharmacol, 18, 205-214.

Trivedi, M. H., \& Greer, T. L. (2014). Cognitive dysfunction in unipolar depression: implications for treatment. J Affect Disord, 152-154, 19-27. 
Vicent-Gil, M., Keymer-Gausset, A., Serra-Blasco, M., Carceller-Sindreu, M., de Diego-Adelino, J., Trujols, J., Mur, M., Perez, V., Alvarez, E., Cardoner, N., \& Portella, M. J. (2018). Cognitive predictors of illness course at 12 months after first-episode of depression. Eur Neuropsychopharmacol, 28, 529-537.

Vieta, E., Sluth, L. B., \& Olsen, C. K. (2018). The effects of vortioxetine on cognitive dysfunction in patients with inadequate response to current antidepressants in major depressive disorder: A short-term, randomized, double-blind, exploratory study versus escitalopram. J Affect Disord, 227, 803-809.

Yoosefi, A., Sepehri, A. S., Kargar, M., Akhondzadeh, S., Sadeghi, M., Rafei, A., Alimadadi, A., \& Ghaeli, P. (2014). Comparing effects of ketamine and thiopental administration during electroconvulsive therapy in patients with major depressive disorder: a randomized, double-blind study. JECT, 30, 15-21.

Table 1. Summary of neurocognitive domains and tests included in cognition studies

\begin{tabular}{|c|c|c|}
\hline Author & \multicolumn{2}{|c|}{$\begin{array}{ll}\text { Cognitive domains tested } & \text { Tests and cognitive tasks used }\end{array}$} \\
\hline \multirow{6}{*}{$\begin{array}{l}\text { Jaeger et } \\
\text { al., } 2006\end{array}$} & Attention/Processing speed & $\begin{array}{l}\text { D2 errors, Stroop Words, Stroop Colours, } \\
\text { TMT Part A, WAIS Digit Symbol Raw }\end{array}$ \\
\hline & Working me & $\begin{array}{l}\text { D2 Fluctuation, WAIS Digit Span Forward, } \\
\text { LNS Total Correct, LNS Long Term, } \\
\text { WAIS Arithmetic Raw, WAIS Digit Span } \\
\text { Backward, WMS Logical Memory }\end{array}$ \\
\hline & Executive function & $\begin{array}{l}\text { WCST Preservatives Errors, COWAT } \\
\text { Correct, Animal Naming }\end{array}$ \\
\hline & Verbal knowledge & $\begin{array}{l}\text { WAIS Vocabulary Raw, WAIS } \\
\text { Comprehension raw, WAIS Similarities } \\
\text { Raw }\end{array}$ \\
\hline & Non-verbal function & $\begin{array}{l}\text { WAIS Block Design Raw, WAIS Picture } \\
\text { Comprehension Raw, WAIS Picture } \\
\text { Arrange Raw }\end{array}$ \\
\hline & Motor & $\begin{array}{l}\text { WMS Verbal Paired I, II, WMS Visual } \\
\text { Paired I, II }\end{array}$ \\
\hline
\end{tabular}




\begin{tabular}{|c|c|c|}
\hline & Learning & $\begin{array}{l}\text { Finger Tap Preferred, Finger Tap Non- } \\
\text { Preferred, Grooved Peg Preferred, Grooved } \\
\text { Pref Non-Preferred }\end{array}$ \\
\hline \multirow{3}{*}{$\begin{array}{l}\text { Preiss et } \\
\text { al., } 2009\end{array}$} & Memory & AVLT \\
\hline & $\begin{array}{l}\text { Attention and psychomotor } \\
\text { speed }\end{array}$ & TMT Part A \\
\hline & Executive functions & TMT Part B \\
\hline $\begin{array}{l}\text { Baune et } \\
\text { al., } 2010\end{array}$ & $\begin{array}{l}\text { Immediate memory, visuospatial } \\
\text { function, language, attention, } \\
\text { delayed memory }\end{array}$ & RBANS \\
\hline \multirow{10}{*}{$\begin{array}{l}\text { Lee et al., } \\
2012\end{array}$} & Psychomotor speed & $\begin{array}{l}\text { TMT Part A, Digit Symbol-Coding, } \\
\text { Symbol Digit Modalities Test }\end{array}$ \\
\hline & Attention & Digit span forwards, spatial span forwards \\
\hline & Working memory & $\begin{array}{l}\text { Digit span backwards; spatial span } \\
\text { backwards }\end{array}$ \\
\hline & Verbal learning & $\begin{array}{l}\text { Logical Memory } 1 \text { and 2, RAVLT, Total \& } \\
\text { Delayed Recall, CVLT-II Total Recall, } \\
\text { Short Delayed Free Recall and Long } \\
\text { Delayed Free Recall, HVLT Total \& } \\
\text { Delayed Recall, Buschke's SRT Total } \\
\text { Recall }\end{array}$ \\
\hline & Visual learning & $\begin{array}{l}\text { Visual Reproduction } 1 \text { and 2; RCFT } 30 \\
\text { Minute Delayed Recall; WMS Visual } \\
\text { Memory Index }\end{array}$ \\
\hline & Attentional switching & TMT B \\
\hline & Verbal fluency & Letter and Semantic Fluency \\
\hline & Cognitive flexibility & $\begin{array}{l}\text { WCST, MCST, CANTAB } \\
\text { Intradimensional/Extradimensional-Shift } \\
\text { (ID/ED) }\end{array}$ \\
\hline & Processing speed & Phonetic fluency, semantic fluency \\
\hline & Verbal memory & List learning, list recall, list recognition \\
\hline
\end{tabular}




\begin{tabular}{|c|c|c|c|c|c|}
\hline & \multicolumn{2}{|c|}{ Executive function } & \multicolumn{3}{|c|}{$\begin{array}{l}\text { Stroop, TMT part B, Planning, WCST } \\
\text { category fluency, WCST preservation }\end{array}$} \\
\hline & \multicolumn{2}{|c|}{ Working memory } & \multicolumn{3}{|c|}{ Digit backwards, digit forwards } \\
\hline \multirow{4}{*}{$\begin{array}{l}\text { Rock et al., } \\
2014\end{array}$} & \multicolumn{2}{|c|}{ Executive function } & \multicolumn{3}{|c|}{ OTS/SOC, SWM, IED, SSP } \\
\hline & \multicolumn{2}{|l|}{ Memory } & \multicolumn{3}{|c|}{ DMS, PAL, PRM, SRM } \\
\hline & \multicolumn{5}{|c|}{$\begin{array}{ll}\text { Attention } & \text { RVP }\end{array}$} \\
\hline & \multicolumn{5}{|c|}{ Reaction time } \\
\hline $\begin{array}{l}\text { McIntyre } \\
\text { et al., } 2017 \\
\text { Cha et al., } \\
2017\end{array}$ & \multicolumn{5}{|c|}{\begin{tabular}{|ll} 
& THINC-it: Spotter Identification Task \\
Executive function, working & (Choice Reaction Time), Symbol Check \\
memory, processing speed, & (One-Back Test), Codebreaker (Digit \\
attention & Symbol Substitution Test), TMT Part B, \\
& IDN, PDQ-5-D
\end{tabular}} \\
\hline \multirow{5}{*}{$\begin{array}{l}\text { Vicent-Gil } \\
\text { et al., } 2018\end{array}$} & \multicolumn{5}{|c|}{$\begin{array}{|ll|}\text { Executive function } & \text { TMT Part B, TOL, WCST, COWAT }\end{array}$} \\
\hline & \multicolumn{5}{|c|}{$\begin{array}{ll}\text { Language } & \text { Semantic verbal fluency test, BNT }\end{array}$} \\
\hline & \multicolumn{5}{|c|}{ Attention and verbal memory Digit torwards, aigit backwards W AIS-III, } \\
\hline & \multicolumn{5}{|c|}{ 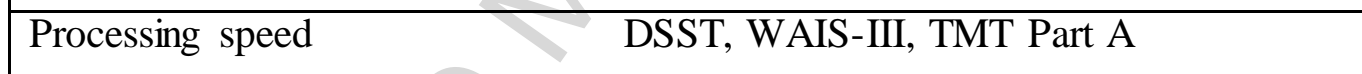 } \\
\hline & \multicolumn{5}{|c|}{$\begin{array}{ll}\text { Verbal learning memory } & \text { RAVLT }\end{array}$} \\
\hline \multicolumn{6}{|c|}{$\begin{array}{l}\text { AVLT=Auditory Verbal Learning Test; BNT=Boston Naming Test; CANTAB=Cambridge } \\
\text { Neuropsychological Test Automated Battery; CPT-II=Continuous Performance test version II; } \\
\text { CVLT-II=California Verbal Learning Test-second edition; COWAT=Controlled Oral Word } \\
\text { Association Test; DMS=Delayed Matching to Sample; HVLT=Hopkins Verbal Learning Test; } \\
\text { IED=Intra-Extra Dimensional Set Shift; IDN=Identification Task; LNS=Letter-Number Sequencing } \\
\text { test; MCST=Modified Card Sorting Test; OTS/SOC=(One Touch) Stockings of Cambridge; } \\
\text { PAL=Paired Associates Learning; PDQ-5-D=Perceived Deficits Questionnaire for Depression-5- } \\
\text { item; PRM=Pattern Recognition Memory; RBANS=Repeatable Battery for the Assessment of } \\
\text { Neuropsychological Status; RCFT=Rey Complex Figure Test; RTI=Reaction Time; RVP=Rapid } \\
\text { Visual Information Processing; SRT=Selective Reminding Test; SRM=Spatial Recognition Memory; } \\
\text { SSP=Spatial Span; SWM=Spatial Working Memory; TMT=Trail Making Test; TOL=Tower of } \\
\text { London; WAIS=Wechsler Adult Intelligence Scale; WCST=Wisconsin Card Sorting Test; } \\
\text { WMS=Wechsler Memory Scale. } \\
\text { Table 2. Characteristics of placebo-controlled trials }\end{array}$} \\
\hline $\begin{array}{c}\text { Autho } \\
\text { r }\end{array}$ & $\begin{array}{l}\text { Treatment } \\
\text { groups }\end{array}$ & $\begin{array}{c}\text { Demographic } \\
\text { s }\end{array}$ & $\begin{array}{c}\text { Depressio } \\
\text { n crite ria }\end{array}$ & $\begin{array}{l}\text { Cognitive } \\
\text { measures }\end{array}$ & $\begin{array}{c}\text { Outco } \\
\text { me }\end{array}$ \\
\hline $\begin{array}{c}\text { Raski } \\
\text { n et } \\
\text { al., } \\
2007\end{array}$ & $\begin{array}{l}\text { loxetine } \\
\text { mg/day } \\
\text { 7) vs PBO } \\
\text { 4) }\end{array}$ & $\begin{array}{l}\text { N=311 } \\
\quad \text { F: } 185 \\
\quad \text { M: } 126 \\
\text { Median age: } \\
72 \\
\text { 65-90 years }\end{array}$ & $\begin{array}{l}\text { Recurrent } \\
\text { MDD } \\
\text { DSM IV } \\
\text { HAM-D } \\
\geq 18 \\
\text { MMSE } \\
\end{array}$ & $\begin{array}{l}\text { Composite } \\
\text { score: } \\
\text { 1. Verbal } \\
\text { Learning } \\
\text { and Recall } \\
\text { Test } \\
\end{array}$ & $\begin{array}{l}\text { Duloxetine patients had } \\
\text { significantly improved } \\
\text { verbal learning and } \\
\text { memory. Executive } \\
\text { function and attention } \\
\text { showed no significant }\end{array}$ \\
\hline
\end{tabular}




\begin{tabular}{|c|c|c|c|c|c|}
\hline & & & $\geq 20$ & $\begin{array}{l}\text { 2. Symbol } \\
\text { Digit } \\
\text { Substitutio } \\
\mathrm{n} \text { Test } \\
\text { 3. Two-Digit } \\
\text { Cancellatio } \\
\mathrm{n} \text { Test } \\
\text { 4.Letter- } \\
\text { Number } \\
\text { Sequencin } \\
\text { g Test }\end{array}$ & change. \\
\hline $\begin{array}{c}\text { Culan } \\
\text { g et } \\
\text { al., } \\
2009\end{array}$ & $\begin{array}{l}\text { Citalopram } \\
\text { 20-40mg (84) } \\
\text { vs PBO (90) } \\
8 \text { weeks }\end{array}$ & $\begin{array}{c}\mathrm{N}=174 \\
\text { F: } 58 \\
\text { M: } 116 \\
\text { Mean age: } 79 \\
\geq 75 \text { years }\end{array}$ & $\begin{array}{l}\text { DSM IV } \\
\text { HAM-D } \\
\geq 20 \\
\text { Non- } \\
\text { psychotic } \\
\text { unipolar } \\
\text { depression }\end{array}$ & $\begin{array}{l}\text { Composite } \\
\text { score: } \\
\text { 1.CRT } \\
\text { 2.JOLO } \\
\text { 3. Stroop test } \\
\text { 4.MMSE } \\
\text { 5.SRT } \\
\text { 6.Digit } \\
\text { Symbol } \\
\text { Subtest }\end{array}$ & $\begin{array}{l}\text { Citalopram non-responders } \\
\text { had worsened learning and } \\
\text { psychomotor speed. } \\
\text { Citalopram responders had } \\
\text { significant improvement in } \\
\text { visuospatial functioning } \\
\text { and psychomotor speed, but } \\
\text { no better than placebo } \\
\text { responders. }\end{array}$ \\
\hline $\begin{array}{l}\text { Reddy } \\
\text { et al., } \\
2016\end{array}$ & $\begin{array}{l}\text { Desvenlafaxin } \\
\text { e } 50 \mathrm{mg}(52) \\
\text { vs PBO (29) } \\
12 \text { weeks }\end{array}$ & $\begin{array}{l}\mathrm{N}=81 \\
\quad \mathrm{~F}: 52 \\
\mathrm{M}: 10 \\
\text { Mean age: } 41 \\
\text { 18-75 years }\end{array}$ & $\begin{array}{l}\text { MDD } \\
\text { MADRS } \\
\geq 25 \\
\text { Baseline } \\
\text { HAM-D } \\
20\end{array}$ & $\begin{array}{l}\text { Composite } \\
\text { scores from } \\
\text { CDR tasks: } \\
\text { 1. Power of } \\
\text { attention } \\
\text { 2. Continuit } \\
\text { y of } \\
\text { attention } \\
\text { 3. Quality } \\
\text { of } \\
\text { working } \\
\text { memory } \\
\text { 4. Speed of } \\
\text { working } \\
\text { memory } \\
\text { TMT A and } \\
\text { B } \\
\text { Stroop test }\end{array}$ & $\begin{array}{l}\text { Desvenlafaxine } \\
\text { significantly improved } \\
\text { performance in working } \\
\text { memory. No significant } \\
\text { difference was reported for } \\
\text { attention. }\end{array}$ \\
\hline $\begin{array}{l}\text { Tian } \\
\text { et al., } \\
2016\end{array}$ & $\begin{array}{l}\text { Venlafaxine } \\
75-150 \mathrm{mg} \\
(34) \\
\text { vs PBO (30) } \\
6 \text { weeks }\end{array}$ & $\begin{array}{l}\mathrm{N}=34 \\
\mathrm{~F}: 24 \\
\text { M:10 } \\
\text { Mean age: } 36\end{array}$ & $\begin{array}{l}\text { MDD } \\
\text { DSM IV } \\
\text { MMSE } \\
>27\end{array}$ & $\begin{array}{l}\text { ANT } \\
\text { MMSE }\end{array}$ & $\begin{array}{l}\text { Selective improvement in } \\
\text { executive control of } \\
\text { attention. No improvement } \\
\text { reported in alerting deficits. }\end{array}$ \\
\hline
\end{tabular}


ANT=Attention Network Test; CDR=Cognitive Drug Research; CRT=Cognitive Reflection Test; DSM-IV=Diagnostic and Statistical Manual of Mental Disorders, 4th Edition; HAM-D=Hamilton Depression Rating Scale; HRSD=Hamilton Rating Scale for Depression; JOLO=Judgment of Line Orientation; MMSE=Mini-Mental State Examination; PBO=Placebo; SRT=Simple Reaction Time; TMT=Trail Making Test

Table 3. Characteristics of active comparator trials

\begin{tabular}{|c|c|c|c|c|c|}
\hline Author & $\begin{array}{c}\text { Treatme } \\
\text { nt } \\
\text { groups }\end{array}$ & $\begin{array}{c}\text { Demograph } \\
\text { ics }\end{array}$ & $\begin{array}{l}\text { Depressi } \\
\text { on } \\
\text { criteria }\end{array}$ & $\begin{array}{l}\text { Cognitive } \\
\text { measures }\end{array}$ & $\begin{array}{l}\text { Outc } \\
\text { ome }\end{array}$ \\
\hline $\begin{array}{l}\text { Doraiswa } \\
\text { my } 2003\end{array}$ & $\begin{array}{l}\text { Sertraline } \\
50 \mathrm{mg} \\
(185) \text { vs } \\
\text { nortriptyli } \\
\text { ne } 25 \mathrm{mg} \\
\text { (96) or } \\
\text { fluoxetine } \\
20 \mathrm{mg} \\
(105) \\
12 \text { weeks }\end{array}$ & $\begin{array}{l}\mathrm{N}=440 \\
\mathrm{~F}: 255 \\
\mathrm{M}: 185 \\
\geq 60 \text { years }\end{array}$ & $\begin{array}{l}\text { MDD } \\
\text { DSM } \\
\text { III=R } \\
\text { HAM-D } \\
\geq 18\end{array}$ & $\begin{array}{l}\text { SLT } \\
\text { DSST } \\
\text { MMSE }\end{array}$ & $\begin{array}{l}\text { Antidepressants } \\
\text { improved SLT and } \\
\text { DSST } \\
\text { performance, but } \\
\text { sertraline showed } \\
\text { greater } \\
\text { improvement in } \\
\text { depression severity } \\
\text { and cognitive } \\
\text { function than } \\
\text { nortriptyline or } \\
\text { fluoxetine. }\end{array}$ \\
\hline $\begin{array}{l}\text { Trick et } \\
\text { al., } 2004\end{array}$ & $\begin{array}{l}\text { Venlafaxin } \\
\text { e } 75 \mathrm{mg} \\
\text { (45) or } \\
\text { dothiepin } \\
75 \mathrm{mg} \mathrm{(43)}\end{array}$ & $\begin{array}{l}\text { N=88 } \\
\quad \text { F:62 } \\
\text { M:26 } \\
\text { Mean age: } 71 \\
\text { 60-83 years }\end{array}$ & $\begin{array}{l}\text { First or } \\
\text { new } \\
\text { episode } \\
\text { MDD } \\
\text { DSM IV } \\
\text { MADRS } \\
\geq 19\end{array}$ & 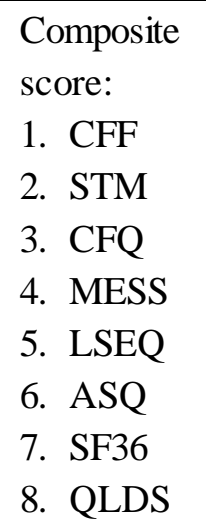 & $\begin{array}{l}\text { Venlafaxine } \\
\text { significantly } \\
\text { improved CFF } \\
\text { scores only. } \\
\text { Dothiepin } \\
\text { significantly } \\
\text { decreased the same } \\
\text { measure. }\end{array}$ \\
\hline $\begin{array}{l}\text { Herrera- } \\
\text { Guzman } \\
\text { et al., 2009 } \\
\text { and } 2010\end{array}$ & $\begin{array}{l}\text { Escitalopra } \\
\mathrm{m} 10 \mathrm{mg} \\
\text { (26) or } \\
\text { duloxetine } \\
60 \mathrm{mg}(37) \\
24 \text { weeks, } \\
\text { and } 24 \\
\text { weeks } \\
\text { follow up }\end{array}$ & $\begin{array}{l}\mathrm{N}=73 \\
\quad \mathrm{~F}: 59 \\
\text { M: } 14 \\
\text { Mean age: } 33 \\
\text { 20-50 years }\end{array}$ & $\begin{array}{l}\text { MDD } \\
\text { DSM IV } \\
\text { HRSD } \geq 18\end{array}$ & $\begin{array}{ll}\text { CANTAB: } \\
\text { 1. WAIS } \\
\text { III digit } \\
\text { span } \\
\text { 2. } \text { RAVLT } \\
\text { 3. } \text { PRM } \\
\text { 4. } \text { PAL } \\
\text { 5. } \text { DMS } \\
\text { 6. SRM } \\
\text { 7. } \text { RTI } \\
\text { 8. } \text { Stroop } \\
\text { test }\end{array}$ & $\begin{array}{l}\text { At } 24 \text { weeks, both } \\
\text { treatments } \\
\text { improved episodic } \\
\text { memory, with } \\
\text { smaller } \\
\text { improvements also } \\
\text { in working } \\
\text { memory, } \\
\text { processing speed, } \\
\text { and motor } \\
\text { performance. } \\
\text { Duloxetine }\end{array}$ \\
\hline
\end{tabular}




\begin{tabular}{|c|c|c|c|c|c|}
\hline & & & & & $\begin{array}{l}\text { improved episodic } \\
\text { memory more } \\
\text { significantly than } \\
\text { escitalopram. At } \\
\text { 24-week follow up, } \\
\text { patients treated } \\
\text { with escitalopram } \\
\text { had lower verbal } \\
\text { and visual memory } \\
\text { performance than } \\
\text { those on } \\
\text { duloxetine. }\end{array}$ \\
\hline $\begin{array}{l}\text { Culang- } \\
\text { Reinleib et } \\
\text { al., } 2012\end{array}$ & $\begin{array}{l}\text { Sertraline } \\
50-200 \mathrm{mg} \\
\text { (33) or } \\
\text { nortriptyli } \\
\text { ne } 1 \mathrm{mg} / \mathrm{kg} \\
(30) \\
\\
12 \text { weeks }\end{array}$ & $\begin{array}{l}\mathrm{N}=63 \\
\mathrm{~F}: 38 \\
\mathrm{M}: 25 \\
\text { Mean age: } 64\end{array}$ & $\begin{array}{l}\text { MDD } \\
\text { DSM IV } \\
H R S D \geq 16 \\
\text { MMSE } \\
\geq 24\end{array}$ & $\begin{array}{l}\text { Composite } \\
\text { score: } \\
\text { 1. MMSE } \\
\text { 2. Purdue } \\
\text { Pegboar } \\
\text { d } \\
\text { 3. CPT } \\
\text { 4. TMT A } \\
\text { and B } \\
\text { 5. SRT } \\
\text { 6. Stroop } \\
\text { test }\end{array}$ & $\begin{array}{l}\text { Sertraline patients } \\
\text { showed significant } \\
\text { improvement in } \\
\text { verbal learning, } \\
\text { and more so than } \\
\text { nortriptyline } \\
\text { patients, who } \\
\text { reported no } \\
\text { improvements. }\end{array}$ \\
\hline $\begin{array}{l}\text { Soczynska } \\
\text { et al., } 2014\end{array}$ & $\begin{array}{l}\text { Bupropion } \\
\text { XL 150- } \\
300 \mathrm{mg} \\
\text { (17) or } \\
\text { escitalopra } \\
\text { m 10- } \\
20 \mathrm{mg} \text { (19) }\end{array}$ & $\begin{array}{l}\text { N=38 } \\
\text { F:19 } \\
\text { M:19 } \\
\text { Mean age: } 38 \\
\text { 18-50 years }\end{array}$ & $\begin{array}{l}\text { MDD } \\
H R S D \geq 16\end{array}$ & $\begin{array}{l}\text { CVLT-II } \\
\text { Wechsler } \\
\text { Memory } \\
\text { Scale } \\
\text { BVMT-R }\end{array}$ & $\begin{array}{l}\text { Both treatments } \\
\text { significantly } \\
\text { improved verbal } \\
\text { and non-verbal } \\
\text { learning and } \\
\text { memory, global } \\
\text { function, and work } \\
\text { productivity. }\end{array}$ \\
\hline $\begin{array}{l}\text { Gorlyn et } \\
\text { al., } 2015\end{array}$ & $\begin{array}{l}\text { Paroxetine } \\
25-50 \mathrm{mg} \\
\text { (30) or } \\
\text { bupropion } \\
150- \\
450 \mathrm{mg} \\
(27) \\
8 \text { weeks }\end{array}$ & $\begin{array}{c}\mathrm{N}=67 \\
\mathrm{~F}: 30 \\
\mathrm{M}: 37 \\
\text { Mean age: } 37\end{array}$ & $\begin{array}{l}\text { MDD } \\
\text { DSM IV } \\
\text { HRSD } \geq 16 \\
\text { Prior } \\
\text { suicide } \\
\text { attempt } \\
\text { and/or } \\
\text { ideation }\end{array}$ & $\begin{array}{l}\text { CFQ } \\
\text { Composite } \\
\text { score: } \\
\text { 1.SRT } \\
\text { 2. CRT } \\
\text { 3. TMT A } \\
\text { and B } \\
\text { 4. WAIS- } \\
\text { III } \\
\text { 5. BVRT } \\
\text { 6. BSRT } \\
\text { 7. N-Back } \\
\text { 8. COWA }\end{array}$ & $\begin{array}{l}\text { Both treatments } \\
\text { improved } \\
\text { neurocognitive } \\
\text { performance across } \\
\text { psychomotor, } \\
\text { attention, memory } \\
\text { and working } \\
\text { memory. } \\
\text { Paroxetine had a } \\
\text { slightly greater } \\
\text { improvement in } \\
\text { psychomotor } \\
\text { speed. }\end{array}$ \\
\hline
\end{tabular}




\begin{tabular}{|c|c|c|c|c|c|}
\hline $\begin{array}{l}\text { Shilyansk } \\
\text { y et al., } \\
2016\end{array}$ & \multirow[b]{2}{*}{$\begin{array}{l}\text { Escitalopra } \\
\mathrm{m} \text { 5-20mg } \\
(336), \text { or } \\
\text { sertraline } \\
12.5- \\
200 \mathrm{mg} \\
(336), \text { or } \\
\text { venlafaxin } \\
\text { e-XR } \\
18.75- \\
225 \mathrm{mg} \\
(336)\end{array}$} & \multicolumn{4}{|c|}{$\begin{array}{l}\mathrm{T} \\
\text { 9. } \mathrm{Go-No} \\
\text { Go }\end{array}$} \\
\hline $\begin{array}{l}\text { Shilyansk } \\
\text { y et al., } \\
2016\end{array}$ & & $\begin{array}{l}\text { N=1008 } \\
\quad \text { F: } 571 \\
\quad \text { M:437 } \\
\text { Mean age: } \\
\text { 37.8 } \\
\text { 18-65 years }\end{array}$ & $\begin{array}{l}\text { First onset } \\
\text { or } \\
\text { recurrent } \\
\text { MDD } \\
\text { DSM IV } \\
\text { HRSD } \geq 17\end{array}$ & $\begin{array}{l}\text { IntegNeuro } \\
\text { battery } \\
\text { 1. CPT } \\
\text { 2. G-No } \\
\text { Go } \\
\text { 3. Verbal } \\
\text { interfere } \\
\text { nce task } \\
\text { 4. Austin } \\
\text { maze } \\
\text { 5. Stroop } \\
\text { task } \\
\text { 6. Forward } \\
\text { digit } \\
\text { span } \\
\text { 7. CRT } \\
\text { 8. TMT A } \\
\text { and B } \\
\text { 9. Finger } \\
\text { tapping }\end{array}$ & $\begin{array}{l}\text { No significant } \\
\text { improvements } \\
\text { reported in } \\
\text { attention, response } \\
\text { inhibition, verbal } \\
\text { memory, decision } \\
\text { speed, or } \\
\text { information } \\
\text { processing. } \\
\text { Where } \\
\text { improvements } \\
\text { occurred, these } \\
\text { were rarely in } \\
\text { more than two } \\
\text { cognitive domains, } \\
\text { and only } 4.5 \% \text { of } \\
\text { patients showed } \\
\text { any broad } \\
\text { cognitive } \\
\text { improvements. }\end{array}$ \\
\hline \multicolumn{6}{|c|}{$\begin{array}{l}\text { ASQ=Ages and Stages Questionnaire; BSRT=Buschke Selective Reminding Test; BVRT=Benton } \\
\text { Visual Retention Test; BVMT-R=Brief Visuospatial Memory Test-Revised; CFF=Critical Flicker } \\
\text { Fusion; CFQ=Cognitive Failures Questionnaire; COWAT=Controlled Oral Word Association Test; } \\
\text { CPT=Continuous Performance test; CVLT-II=California Verbal Learning Test-second edition; } \\
\text { DMS=Delayed Matching to Sample; DSST=Digit Symbol Substitution Test; HRSD=Hamilton } \\
\text { Rating Scale for Depression; LSEQ= Leeds Sleep Evaluation Questionnaire; MADRS=Montgomery- } \\
\text { Àsberg Depression Rating Scale; MESS=Milford-Epworth Sleepiness Scale; MMSE=Mini-Mental } \\
\text { State Examination; PAL=Paired Associates Learning; PBO=Placebo; PRM=Pattern Recognition } \\
\text { Memory; RTI=Reaction Time; SLT=Shopping List Task; SRM=Spatial Recognition Memory; } \\
\text { SRT=Selective Reminding Test; STM=Short Term Memory; SF36=Short Form 36 (SF-36) Health } \\
\text { Survey; QLDS=Quality of Life in Depression Scale; RAVLT=Rey Auditory Verbal Learning Test; } \\
\text { TMT= Trail Making Test; WAIS-III=Wechsler Adult Intelligence Scale } \\
\text { Table 4: Characteristics for novel antidepressant trials }\end{array}$} \\
\hline Author & $\begin{array}{l}\text { Treatm } \\
\text { ent } \\
\text { groups }\end{array}$ & $\begin{array}{l}\text { Demograp } \\
\text { hics }\end{array}$ & $\begin{array}{l}\text { Depress } \\
\text { ion } \\
\text { criteria }\end{array}$ & $\begin{array}{l}\text { Cognitive } \\
\text { measures }\end{array}$ & $\begin{array}{l}\mathbf{O} \\
\text { ut } \\
\text { co } \\
\mathbf{m} \\
\text { e }\end{array}$ \\
\hline
\end{tabular}




\begin{tabular}{|c|c|c|c|c|c|}
\hline $\begin{array}{l}\text { Katona et al., } \\
2012\end{array}$ & $\begin{array}{l}\text { Vortioxe } \\
\text { tine } 5 \mathrm{mg} \\
(156) \mathrm{vs} \\
\text { duloxetin } \\
\text { e } 60 \mathrm{mg} \\
(151) \mathrm{vs} \\
\text { PBO } \\
(145) \\
8 \text { weeks }\end{array}$ & 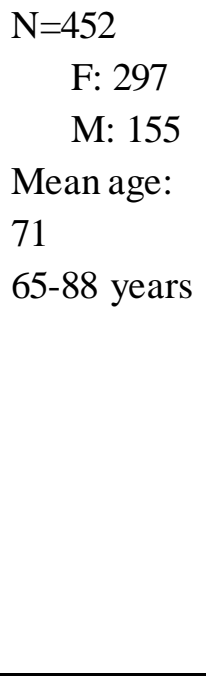 & $\begin{array}{l}\text { Acute } \\
\text { MDD } \\
\text { DSM IV } \\
\text { MADRS } \\
\geq 26\end{array}$ & $\begin{array}{l}\text { Composite score: } \\
\text { 1.RAVLT } \\
\text { 2.DSST }\end{array}$ & $\begin{array}{l}\text { Vortioxetine } \\
\text { significantly } \\
\text { improved } \\
\text { scores testing } \\
\text { processing } \\
\text { speed, verbal } \\
\text { learning and } \\
\text { memory, with } \\
\text { more direct } \\
\text { effects on } \\
\text { DSST and } \\
\text { RAVLT than } \\
\text { duloxetine. }\end{array}$ \\
\hline $\begin{array}{l}\text { McIntyre et } \\
\text { al., } 2014\end{array}$ & $\begin{array}{l}\text { Vortioxe } \\
\text { tine } \\
10 \mathrm{mg} \\
(195), \\
20 \mathrm{mg} \\
(207) \mathrm{vs} \\
\text { PBO } \\
(196) \\
8 \text { weeks }\end{array}$ & $\begin{array}{l}\text { N=598 } \\
\text { F:396 } \\
\text { M:202 } \\
\text { Mean age: } \\
45 \\
\text { 18-65 years }\end{array}$ & $\begin{array}{l}\text { Acute } \\
\text { MDD } \\
\text { DSM IV- } \\
\text { TR } \\
\text { MADRS } \\
\geq 26\end{array}$ & $\begin{array}{l}\text { Composite score: } \\
\text { 1. DSST } \\
\text { 2. RAVLT } \\
\text { 3. TMT A and B } \\
\text { 4. Stroop Test } \\
\text { 5. SRT } \\
\text { 6. CRT } \\
\text { 7. PDQ } \\
\text { 8. } \text { MADRS } \\
\text { 9. } \text { CGI-S }\end{array}$ & $\begin{array}{l}\text { Objective } \\
\text { measures } \\
\text { reported } \\
\text { improvement } \\
\text { vs PBO in } \\
\text { executive } \\
\text { function, } \\
\text { attention, } \\
\text { processing } \\
\text { speed, learning } \\
\text { and memory. } \\
\text { Subjective } \\
\text { measures } \\
\text { reported } \\
\text { improvement in } \\
\text { memory, } \\
\text { attention/conce } \\
\text { ntration, and } \\
\text { planning/organi } \\
\text { zation }\end{array}$ \\
\hline $\begin{array}{l}\text { Mahableshw } \\
\text { arkar et al., } \\
2015\end{array}$ & $\begin{array}{l}\text { Vortioxe } \\
\text { tine } 10- \\
20 \mathrm{mg} \\
(198) \text { vs } \\
\text { duloxetin } \\
\text { e 60mg } \\
(210) \text { vs } \\
\text { PBO } \\
(194) \\
8 \text { weeks }\end{array}$ & $\begin{array}{l}\mathrm{N}=602 \\
\mathrm{~F}: 392 \\
\text { M: } 210 \\
\text { Mean age: } \\
45 \\
\text { Age range: } \\
\text { 18-65 }\end{array}$ & $\begin{array}{l}\text { DSM-IV- } \\
\text { TR } \\
\text { Acute } \\
\text { MDD }\end{array}$ & $\begin{aligned} & \text { Composite } \\
& \text { score: } \\
& \text { 1. } \text { DSST } \\
& \text { 2. } \text { TMT A } \\
& \text { and B } \\
& \text { 3. } \text { Stroop } \\
& \text { Test } \\
& \text { 4. } \text { GMLT } \\
& \text { 5. } \text { Detection } \\
& \text { Task } \\
& \text { 6. } \text { Identificati } \\
& \text { on Task } \\
& \text { 7. } \text { One-Back }\end{aligned}$ & $\begin{array}{l}\text { Significant } \\
\text { improvement in } \\
\text { DSST and } \\
\text { TMT-B, } \\
\text { processing } \\
\text { speed and } \\
\text { executive } \\
\text { function } \\
\text { Improved PDQ }\end{array}$ \\
\hline
\end{tabular}




\begin{tabular}{|c|c|c|c|c|c|}
\hline & & & & $\begin{array}{l}\quad \text { Task } \\
\text { PDQ } \\
\text { CPFQ }\end{array}$ & \\
\hline $\begin{array}{l}\text { Harrison et } \\
\text { al., } 2016\end{array}$ & $\begin{array}{l}\text { Vortioxe } \\
\text { tine } \\
10 \mathrm{mg} \\
(200), \\
20 \mathrm{mg} \\
(200) \text { vs } \\
\text { PBO } \\
(200) \\
8 \text { weeks }\end{array}$ & $\begin{array}{l}\mathrm{N}=602 \\
18-65 \text { years }\end{array}$ & $\begin{array}{l}\text { MDD } \\
\text { DSM IV }\end{array}$ & $\begin{aligned} & \text { Composite } \\
& \text { score: } \\
& \text { 1. } \\
& \text { 2. } \text { RAST } \\
& \text { 3. } \text { TMT A } \\
& \text { and B } \\
& \text { 4. } \text { Stroop } \\
& \text { Test } \\
& \text { 5. } \text { SRT } \\
& \text { 6. } \text { CRT } \\
&\end{aligned}$ & $\begin{array}{l}\text { Improved } \\
\text { cognitive } \\
\text { performance in } \\
\text { executive } \\
\text { function, } \\
\text { attention/speed } \\
\text { of processing, } \\
\text { and memory. }\end{array}$ \\
\hline $\begin{array}{l}\text { Smith et al., } \\
2018\end{array}$ & $\begin{array}{l}\text { Vortioxe } \\
\text { tine } \\
20 \mathrm{mg} \\
(48) \text { vs } \\
\text { PBO } \\
(48) \\
2 \text { weeks }\end{array}$ & $\begin{array}{l}\mathrm{N}=96 \\
\quad \mathrm{~F}: 53 \\
\quad \text { M: } 43 \\
\text { Mean age: } \\
35 \\
\text { 20-53 years }\end{array}$ & $\begin{array}{l}\text { Remitted } \\
\text { MDD } \\
\text { DSM IV }\end{array}$ & $\begin{array}{l}\text { Composite } \\
\text { score: } \\
\text { 1. DSST } \\
\text { 2. RAVLT } \\
\text { 3. TMT A } \\
\text { and B } \\
\text { N-back fMRI task } \\
\text { PDQ }\end{array}$ & $\begin{array}{l}\text { Vortioxetine } \\
\text { reduced neural } \\
\text { activity in right } \\
\text { dlPFC and left } \\
\text { hippocampus, } \\
\text { and a network } \\
\text { of temporal- } \\
\text { parietal areas } \\
\text { important for } \\
\text { executive } \\
\text { function and } \\
\text { working } \\
\text { memory } \\
\text { Improved TMT } \\
\text { performance }\end{array}$ \\
\hline $\begin{array}{l}\text { Vieta et al., } \\
2018\end{array}$ & $\begin{array}{l}\text { Vortioxe } \\
\text { tine } 10- \\
20 \mathrm{mg} \\
(50) \text { or } \\
\text { escitalop } \\
\text { ram 10- } \\
20 \mathrm{mg} \\
(49) \\
8 \text { weeks }\end{array}$ & $\begin{array}{l}\mathrm{N}=99 \\
\mathrm{~F}: 74 \\
\text { M: } 25 \\
\text { Mean age: } \\
48 \\
18-65 \text { years }\end{array}$ & $\begin{array}{l}\text { MDD } \\
\text { DSM-IV- } \\
\text { TR } \\
\text { Inadequa } \\
\text { te } \\
\text { response } \\
\text { to } 6 \\
\text { weeks of } \\
\text { SSRI or } \\
\text { SNRI } \\
\text { treatment } \\
\text { MADRS } \\
\geq 26 \\
\text { PHQ-9 } \\
\geq 14 \\
\text { PDQ-D } \\
\geq 25 \\
\end{array}$ & $\begin{array}{l}\text { UPSA-B } \\
\text { PDQ-D } \\
\text { Composite } \\
\text { score: } \\
\text { 1. } \\
\text { 2. } \text { TMST A and } \\
\text { B } \\
\text { 3. SRT } \\
\text { 4. } \\
\text { 5. } \\
\text { 6. } \\
\text { 6. Stroop Test }\end{array}$ & $\begin{array}{l}\text { DSST and } \\
\text { UPSA-B } \\
\text { performance } \\
\text { improved in } \\
\text { both groups. } \\
\text { Improvements } \\
\text { in seven } \\
\text { domains } \\
\text { favoured } \\
\text { vortioxetine, } \\
\text { with the } \\
\text { exception of } \\
\text { TMT-A and } \\
\text { SRT. }\end{array}$ \\
\hline Chen et al., & $0.2 \mathrm{mg} / \mathrm{kg}$ & $\mathrm{N}=71$ & DSM-IV & Working memory & $0.2 \mathrm{mg} / \mathrm{kg}$ \\
\hline
\end{tabular}




\begin{tabular}{|c|c|c|c|c|c|}
\hline 2018 & $\begin{array}{l}\text { ketamine } \\
(23), \\
0.5 \mathrm{mg} / \mathrm{kg} \\
\text { ketamine } \\
(24), \text { or } \\
\text { PBO } \\
\text { normal } \\
\text { saline } \\
(24) \\
\\
2 \text { weeks }\end{array}$ & $\begin{array}{l}\text { F: } 53 \\
\text { M: } 18 \\
\text { Mean age: } \\
47.35 \\
21-65 \text { years }\end{array}$ & $\begin{array}{l}\text { TRD } \\
\text { HDRS } 23\end{array}$ & $\begin{array}{l}\text { task } \\
\text { Go/No-Go Task }\end{array}$ & $\begin{array}{l}\text { ketamine did } \\
\text { not impair } \\
\text { cognitive } \\
\text { function. } \\
0.5 \mathrm{mg} / \mathrm{kg} \\
\text { ketamine } \\
\text { improved } \\
\text { attention and } \\
\text { response } \\
\text { control in } \\
\text { go/no-go task } \\
\text { performance, } \\
\text { with negative } \\
\text { correlation with } \\
\text { depression } \\
\text { symptoms } \\
\text { suggesting this } \\
\text { antidepressant } \\
\text { effect improved } \\
\text { cognition. }\end{array}$ \\
\hline
\end{tabular}

CGI-S=Clinical Global Impression-Severity scale; $\mathrm{CPFQ}=\mathrm{Cognitive}$ and Physical Functioning Questionnaire; CRT=Cognitive Reflection Test; DSST=Digit Symbol Substitution Test; EWPS=Endicott Work Productivity Scale; GMLT=Groton Maze Learning Test; MADRS= Montgomery-Åsberg Depression Rating Scale; RAVLT=Rey Auditory Verbal Learning Test; SRT=Selective Reminding Test; $\mathrm{PBO}=$ Placebo; $\mathrm{PDQ}=$ Perceived Deficits Questionnaire; $\mathrm{TMT}=$ Trail Making Test; UPSA-B=UCSD Performance-Based Skills Assessment; WLQ-25=The Work Limitations Questionnaire

Table 5 - Characte ristics for novel therapies with cognitive outcomes

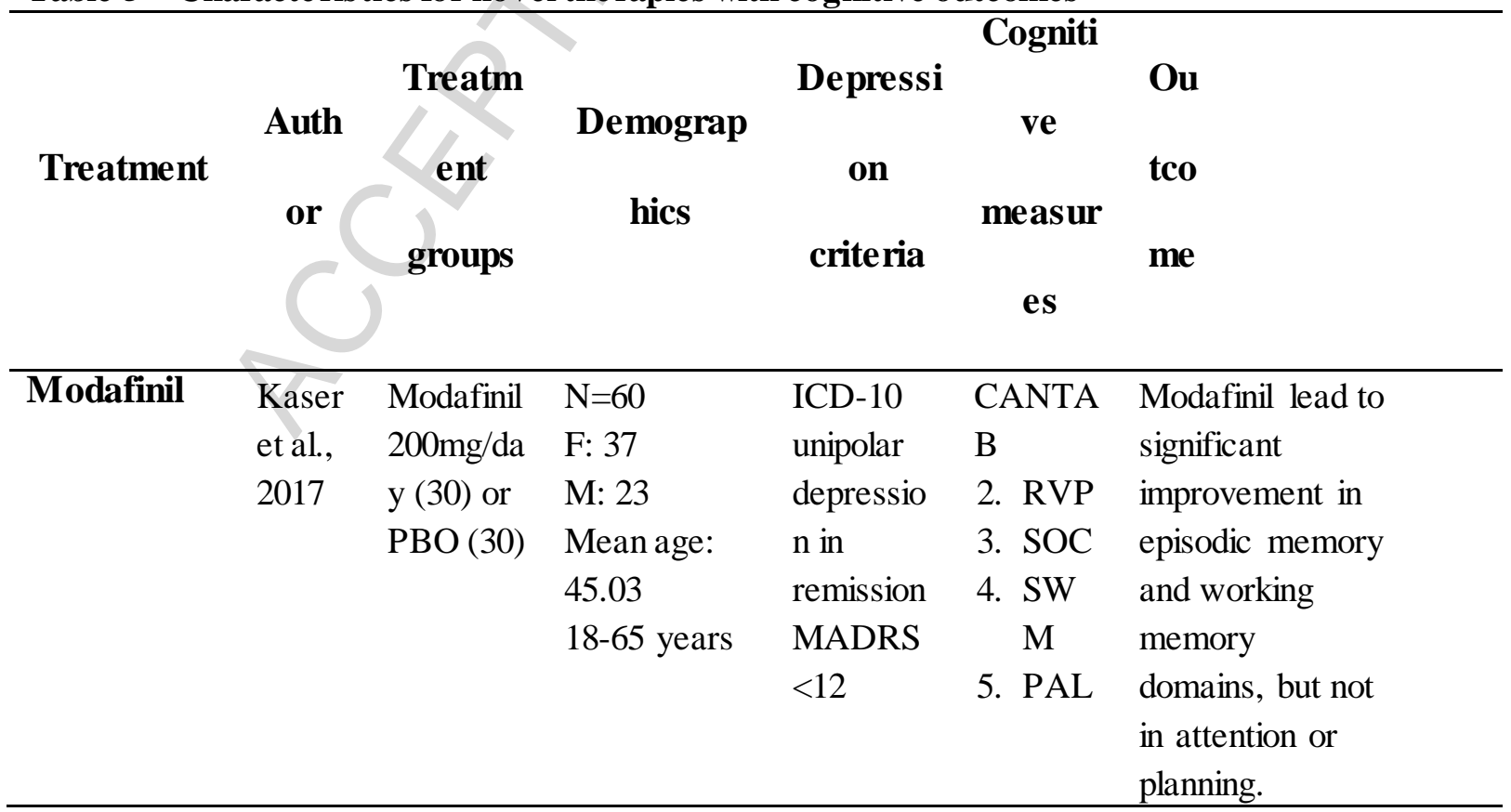




\begin{tabular}{lllllll}
\hline Erythropoi & Ott et & 8-weekly & N=79 & N=36 & RAVLT & EPO improved \\
etin (EPO) & al., & EPO & F: 55 & with UD & RBANS & processing speed \\
& 2016 & 40,000 & M: 24 & N=43 & WAIS- & in attention, \\
& & IU/ml & Mean age: & with BD & III & memory, and \\
& & (40) or & 42 & HDRS & TMT-B & executive \\
& saline & & $\geq 17$ & RVP & function in both \\
& NaCl & & TRAQ & CPFQ & groups, which \\
& $0.9 \%$ & & & was maintained \\
& infusions & & & at 6-week follow \\
& & & & & up. \\
& & & & &
\end{tabular}

$\mathrm{CPFQ}=$ Cognitive and Physical Functioning Questionnaire; PAL= Paired Associates Learning; RVP= Rapid Visual Information Processing; SOC=Stockings of Cambridge; SWM=Spatial Working Memory; TMT=Trail Making Test; WCST=Wisconsin Card Sorting Test; WMS-III=Wechsler Memory Scale; WAIS-III=Wechsler Adult Intelligence Scale; VLMT=VerbalLearning and Memory Test; VRMD= Verbal recognition memory - delayed; VRMI=Verbal recognition memory immediate.

\section{Figure 1}

Figure 2

Figure 3 